\title{
Understanding Hurricane Storm Surge Generation and Propagation Using a Forecasting Model, Forecast Advisories and Best Track in a Wind Model, and Observed Data-Case Study Hurricane Rita
}

\author{
Abram Musinguzi ${ }^{1}$, Muhammad K. Akbar ${ }^{2, *}$, Jason G. Fleming ${ }^{3}$ and Samuel K. Hargrove ${ }^{2}$ \\ 1 Department of Civil and Architectural Engineering, Tennessee State University, Nashville, TN 37209, USA; \\ amusingu@my.tnstate.edu \\ 2 Department of Mechanical and Manufacturing Engineering, Tennessee State University, \\ Nashville, TN 37209, USA; skhargrove@tnstate.edu \\ 3 Seahorse Coastal Consulting, 3103 Mandy Ln, Morehead City, NC 28557, USA; \\ jason.fleming@seahorsecoastal.com \\ * Correspondence: makbar@tnstate.edu; Tel.: +1-615-963-5392
}

Received: 22 February 2019; Accepted: 15 March 2019; Published: 21 March 2019

\begin{abstract}
Meteorological forcing is the primary driving force and primary source of errors for storm surge forecasting. The objective of this study was to learn how forecasted meteorological forcing influences storm surge generation and propagation during a hurricane so that storm surge models can be reliably used to forecast actual events. Hindcasts and forecasts of Hurricane Rita (2005) storm surge was used as a case study. Meteorological forcing or surface wind/pressure fields for Hurricane Rita were generated using both the Weather Research and Forecasting (WRF) full-scale forecasting model along with archived hurricane advisories ingested into a sophisticated parametric wind model, namely Generalized Asymmetric Holland Model (GAHM). These wind fields were used to forecast Rita storm surges. Observation based wind fields from the OceanWeather Inc. (OWI) Interactive Objective Kinematic Analysis (IOKA) model, and Best track wind data ingested into the GAHM model were used to generate wind fields for comparison purposes. These wind fields were all used to hindcast Rita storm surges with the ADvanced CIRCulation (ADCIRC) model coupled with the Simulating Waves Nearshore (SWAN) model in a tightly coupled storm surge-wave model referred to as ADCIRC+SWAN. The surge results were compared against a quality-controlled database of observed data to assess the performance of these wind fields on storm surge generation and propagation. The surge hindcast produced by the OWI wind field performed the best, although some high water mark (HWM) locations were overpredicted. Although somewhat underpredicted, the WRF wind fields forecasted wider surge extent and wetted most HWM locations. The hindcast using the Best track parameters in the GAHM and the forecast using forecast/advisories from the National Hurricane Center (NHC) in the GAHM produced strong and narrow wind fields causing localized high surges, which resulted in overprediction near landfall while many HWM locations away from wind bands remained dry.
\end{abstract}

Keywords: storm surge generation and propagation; weather research and forecasting model; hurricane advisories and Best track; Generalized Asymmetric Holland Model; circulation and wave coupled model; hurricane forecast and hindcast

\section{Introduction}

A hurricane brings extreme winds, rain, waves, storm surges and flooding, especially during its land-fall. To avoid loss of life and properties due to storm surge, evacuation protocols have been 
developed in US coastal regions [1]. To predict storm surge and overland floods, two fundamentally different approaches can be used [2]: (a) pre-generated composite storm surges stored in a database, and (b) real-time simulation-based forecasting. The pre-generated composite approach uses a set of climatologically generated synthetic hurricanes that can affect a particular coastal region. Storm surges can then be predicted based on the current hurricane forecast, and the pre-generated storm surge of the closest match can be chosen through a table lookup or using a statistical method [3-7]. While this method is very fast, its accuracy is limited due to the variability of the wind and track parameters of the current hurricane [1]. The second method uses a storm surge hydrodynamic model in real-time based on the hurricane forecasts [2,8-15]. It accounts for the wind parameters and tracks of the actual hurricane on hand, although the resolution and model domain may be limited by the computational resources available. The meteorological forcing needed in this approach can be created from a full-scale meteorological forecasting model [16-18], parametric vortex model [19-26], or coupled multi-physics model [27-32]. The parametric wind model is the simplest and fastest option, which can re-create the wind fields and surface pressure from a limited amount of storm parameters that are typically reported in advisories or the Best track. These approaches assume the wind is unaffected by waves or ocean circulation, which may not be the most accurate option [27-32], however, it is widely used [19-26]. Observational wind fields, such as OceanWeather Inc. (OWI) [24] and Hurricane WIND (HWIND) [26], that are typically used for storm surge hindcast are fundamentally different than those used in prediction models. More importantly, observational wind fields are not available during an actual forecasting period.

Although the hindcasting of hurricane storm surges is reasonably accurate [14,33-36], the uncertainties associated with hurricane tracks, intensities, sizes, and structures in a forecasting situation are substantially larger, which inevitably impacts the associated storm surges $[2,12,37]$. Therefore, emergency management almost always resorts to a conservative approach of over prediction of the surge during the decision-making process [2]. Although it is known that hurricane meteorological forcing is the main bottleneck in prediction of storm surge development and propagation, limited studies have been published that quantify how well forecast advisories perform against that of a full scale forecasting model $[8,38]$ or against that of a fully coupled forecasting model [12]. How these forecasting results compare against those from observation based or parametric wind models are not fully understood either. Moreover, hurricanes are often structurally and geographically different from each other, and a generalized forecasting approach may not yet be possible.

A variety of numerical and statistical models have been developed for forecasting and/or hindcasting hurricane wind fields (e.g., [39-44]). The most common approaches used in surface wind modeling for tropical cyclones may be categorized as:

(a) Simple analytical parametric models, such as the original Holland model [19]. Such models can be used for both hindcast and forecast of hurricane storm surges, depending on the type of wind data ingested.

(b) Dynamical models such as the Planetary Boundary Layer (PBL) model of Chow [20] as later implemented by Cardone et al. [21], Shapiro [45], Thompson and Cardone [22], and Vickery et al. [23]; the Dynamic Holland Model [46], the Asymmetric Holland Model [47,48] and Generalized Asymmetric Holland Model (GAHM) [49]. These can be used for both hindcast and forecast of hurricane storm surges, depending on the type of wind data ingested.

(c) Full scale physics-based dynamical models such as Fifth-Generation Penn State/NCAR Mesoscale Model (MM5) [16], Geophysical Fluid Dynamics Laboratory (GFDL) model [17], and Weather Research and Forecasting (WRF) model [18]. These can primarily be used to forecast the hurricane storm surges.

(d) Kinematical methods, most notably Hurricane WIND (HWIND) [26] Interactive Objective Kinematic Analysis (IOKA) by OWI [24,25]. These are primarily used to hindcast hurricane storm surges. 
In this study a numerical experiment is done with different wind fields from OWI, Best track ingested in GAHM, WRF forecasting, and advisories ingested in GAHM model. Wind fields from these are used as meteorological forcing to forecast and hindcast Hurricane Rita's storm surge using the ADvanced CIRCulation (ADCIRC) + Simulating Waves Nearshore (SWAN) coupled model. The results are compared against observed data to understand the hurricane storm surge generation and propagation with the objective of improved forecasting capabilities during an actual event.

The rest of the paper is organized as follows: Section 2 presents model details, Section 3 presents simulation cases and capability criteria, Section 4 presents results and discussion, and finally, Section 5 presents concluding remarks.

\section{Model Details}

\subsection{Hydrodynamic Model and Model Mesh}

The ADCIRC+SWAN is a tightly-coupled model that simulated hurricane storm surge and wave generation and propagation. It is an unstructured grid, finite element-based ocean circulation model that solves the equations of moving fluid on a rotating earth [50-53]. The ADCIRC model solves shallow-water equations to model hurricane storm surges. The SWAN model is a third-generation wave model [54] which is tightly coupled with ADCIRC to produce random, short-crested wind-generated waves on top of storm surges. The SWAN+ADCIRC model takes atmospheric pressure and horizontal wind velocity to compute water surface elevation, depth-integrated velocity, significant wave height, and wave period.

The ADCIRC+SWAN model is used to hindcast and forecast the storm surge of Hurricane Rita (2005). Hurricane Rita formed on 18 September and hit the coast of southwestern Louisiana at a Category 3 at 0740 Coordinated Universal Time (UTC) 24 September of 2005 [55]. On arrival into the Gulf of Mexico, Rita rapidly strengthened to a Category 5. Gradually, it weakened to Category 4 and then maintained a Category 3 status up to the time of landfall between Sabine Pass, Texas and Holy Beach, Louisiana [55]. The spread of the surge extended from the Mississippi coast in the east and Port O'Connor region (a small unincorporated village between Galveston and Corpus Christi in Texas) in the west.

The Rita hindcast conducted by Kerr et al. [56] using ADCIRC+SWAN using the OWI wind field is taken as the default case in the present study. However, the semi-implicit solver option of ADCIRC is adopted in the present study, instead of the lumped-explicit one used by Kerr et al. The ULtralite-Levee-Removed (ULLR) mesh (417,642 nodes, 826,866 linear triangular elements), created by Kerr et al. as a part of the U.S. IOOS Coastal and Ocean Modeling Testbed [56], is used to run ADCIRC+SWAN (see Figure 1a). Note that this mesh does not have levees because it was originally created to compare different storm surge models [56] and some of those do not have levee overflow features implemented. Since the present study is a comparative study and the region of study for Hurricane Rita is away from major levee systems of Louisiana, the usage of ULLR mesh here is well justified. The region of interest along with Hurricane Rita's track is shown in Figure 1b. A spatially varying distribution of Manning's roughness coefficient derived from land-use databases, as listed in [56], is used for computing the bottom friction in ADCIRC. The same spatially varying Manning's n coefficients are exported to use in SWAN. 

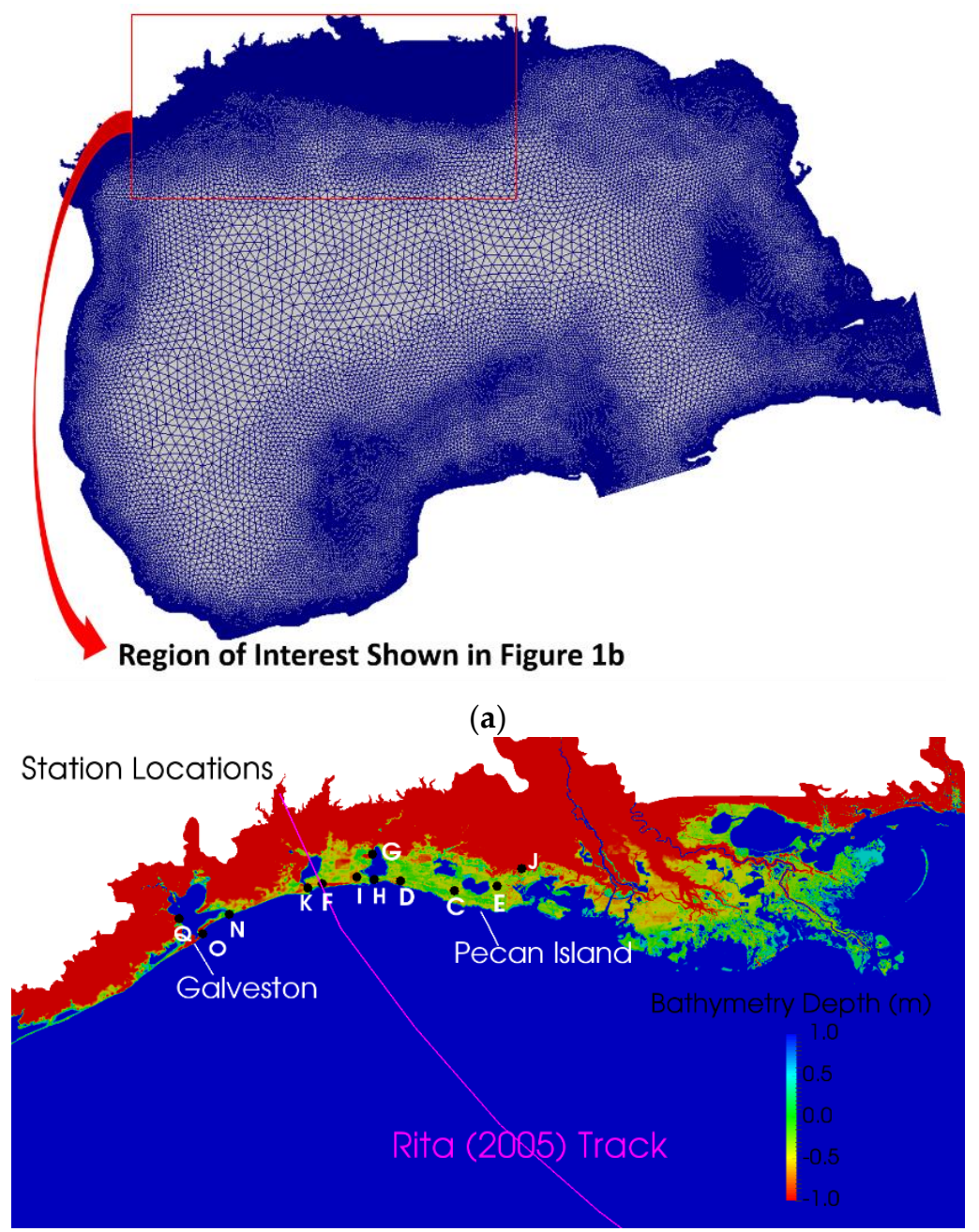

(b)

Figure 1. Unstructured ULtralite-Levee-Removed (ULLR) [56] mesh (a) resolution; (b) observation station locations with respect to Hurricane Rita track. Note that the bathymetry is artificially constrained to be between $1 \mathrm{~m}$ and $-1 \mathrm{~m}$ to delineate the shoreline. Here a negative bathymetry represents above sea level.

\subsection{Meteorological Forcing}

In Section 1 different approaches for obtaining hurricane winds are discussed. In this section, more details of the wind models applied in the present study are discussed. In a similar approach to Kerr et al. [56], the first and default wind model used here is the OWI, a kinematical model. In this model, the structured and data-assimilated wind and pressure fields for Rita are generated by blending the TC96 (short for Thompson and Cardone, 1996) mesoscale model [22], with an inner core wind field transformed to $30 \mathrm{~min}$ averaged sustained winds with gulf scale winds using the IOKA system [24,25]. The hindcast winds use measurements from anemometers, airborne and land-based Doppler radar, microwave radiometers, buoys, ships, aircraft, coastal stations, and satellite measurements. The OWI wind fields are typically available only for hindcast of hurricane storm surge. Therefore, OWI is used for hindcast of the whole or segment of surge for which the wind information is supposed to be known.

The second wind field to be used in the present study for the hindcast of the surge is the Best track data ingested in the GAHM model. Hurricane Best track or forecast data contains some basic information, including eye location and time, maximum wind speed and radius, and central pressure. The Dynamic Holland model [19] calculates some parameters from those data to apply in empirical equations to calculate the atmospheric pressure and gradient wind velocity, from which wind velocity 
at $10 \mathrm{~m}$ height is calculated [46]. This model assumes symmetric distribution of the wind field. However, hurricanes often have asymmetric wind field distributions. The Asymmetric Holland Model (AHM) uses either R64, R50, or R34 distance to strongest wind isotach (i.e., $64 \mathrm{kt}, 50 \mathrm{kt}$, or $34 \mathrm{kt}$ away from the eye) to solve for a different maximum radius in each storm quadrant (NE, NW, SW, SE) [47,48]. In other words, the AHM uses the single strongest isotach in each quadrant. The AHM is a significant improvement over the Dynamic Holland Model. A further improvement over the AHM model is the GAHM [49]. The GAHM is an adaptation from the asymmetric Holland model $[47,48]$ that has been modified to use information from all available isotachs, and the wind structure information includes radii of maximum winds for the 34, 50, 64, and 100 knots isotachs reported [57] in the four quadrants (NE, SE, SW, and NW).

The third wind data sets to be used for the forecast of storm surge are produced from WRF, a numerical weather forecasting model, which is designed to serve both operational forecasting and atmospheric research needs $[18,44,58]$. The atmosphere is a fluid of air parcels in constant motion, which turns completely chaotic during a hurricane. Mathematical equations are derived to describe various motions and interactions that occur in the atmosphere and oceans. The WRF model numerically solves those equations. WRF needs a domain of study, its topological and geographical features, meteorological initial and boundary conditions, etc. The output of WRF includes hurricane wind velocities and free surface pressure, which are the input for ADCIRC+SWAN. WRF is known to generate reasonable details of hurricane dynamics [59]. The WRF model configuration used in the present study is presented below in Table 1 , which is taken from literature [30,32,60].

Table 1. Weather Research and Forecasting (WRF) model configuration.

\begin{tabular}{cc}
\hline Parameter & Configuration \\
\hline Initial conditions & NCEP $1^{\circ}$ by $1^{\circ}$ final analysis (FNL) \\
Map projection & Lambert \\
Horizontal grid distance & $15 \mathrm{~km}$ \\
NCEP time interval & $6 \mathrm{~h}$ \\
Time step & 60 \\
Microphysics & WSM 6 \\
Longwave radiation & RRTM \\
Shortwave radiation & Dudhia \\
Cumulus parameterization & Kain-Fritsch \\
PBL parameterization & Yonsei University (YSU) scheme \\
Land Surface option & NOAH land surface model \\
\hline
\end{tabular}

The fourth wind products to be used for forecast of storm surges are the archived advisories of Hurricane Rita ingested in the GAHM wind model. Advisories contain some basic information of the forecasted hurricane including projected eye location, time, maximum wind speed, hurricane radius, and estimated minimum central pressure. The GAHM wind model produces wind and pressure fields from the limited advisory data.

The impact of meteorological forcing from abovementioned hindcast and forecast sources on the generation and propagation of storm surges is investigated. High fidelity spatially varying nodal attributes of Manning's roughness coefficient, directional roughness length, primitive weighting in continuity equations, etc., tidal, and lateral boundary conditions are used and kept same for all runs to rule out their influences on the comparative study. The wind drag coefficient formulation due to Powell [61] with a cap of $\mathrm{Cd} \leq 0.002$ is used in both ADCIRC and SWAN. The main tidal constituents, $\mathrm{K} 1, \mathrm{O} 1, \mathrm{Q} 1, \mathrm{P} 1, \mathrm{M} 2, \mathrm{~K} 2, \mathrm{~N} 2$, and S2 are generated from the EC2001 tidal database [62,63].

\section{Simulation Cases and Capability Criteria}

Two hindcast simulations using wind fields from OWI and Best track ingested in GAHM, and ten forecast simulations using wind fields from WRF and advisories ingested in GAHM were performed 
in this study. The starting dates for WRF forecast and advisory cases range from 3.5 days to 0.2 days before the landfall. Since ADCIRC+SWAN needs a longer run duration, wind fields of the earlier part of the hurricane are filled in with OWI, which are supposed to be already known at the beginning of the forecast. Alternatively, the Best track wind data ingested in GAHM model could be used instead of the OWI wind field for the pre-forecast durations. Each simulation is cold started on 0000 UTC 13 August 2005, with a 36-day tides-only period that allows the tides to reach a dynamic equilibrium. This is followed by a 7.2-day Rita simulation from 0000 UTC 18 September of 2005 to 0500 UTC 26 September of 2005. That means the OWI wind field is used from 0000 UTC 18 September of 2005 until the WRF forecast and advisory starting times. Qualitative and quantitative comparisons using water level time series and high-water marks (HWM) of simulated results and observed data are presented for the station locations (see Table 2). These observation station locations with respect to the Hurricane Rita track are shown in Figure 1b. Eight stations are located on the right (or east), and four stations are on the left (or west) side of the track.

Table 2. Locations of United States Geological Survey (USGS) [64] Deployed (DEPL) observation stations. Note: LA10, LC13, LF5, etc. are identification tags for station locations.

\begin{tabular}{cccc}
\hline ID & Station & Longitude $\left(^{\circ}\right)$ & Latitude $\left(^{\circ}\right)$ \\
\hline C & USGS-DEPL LA10 & -92.67552 & 29.70658 \\
D & USGS-DEPL LA12 & -93.11494 & 29.7861 \\
E & USGS-DEPL LA9 & -92.32792 & 29.74476 \\
F & USGS-DEPL LC13 & -93.75285 & 29.76407 \\
G & USGS-DEPL LC6a & -93.34333 & 30.00432 \\
H & USGS-DEPL LC8a & -93.32886 & 29.79764 \\
I & USGS-DEPL LC9 & -93.47052 & 29.81823 \\
J & USGS-DEPL LF5 & -92.12703 & 29.88604 \\
8770570 & Sabine Pass North, TX & -93.87000 & 29.72833 \\
8770971 & Rollover Pass, TX & -94.51000 & 29.51500 \\
8771341 & Galveston Bay Entrance, North Jetty, TX & -94.72500 & 29.35667 \\
8771013 & Eagle Point, Galveston Bay, TX & -94.91833 & 29.48000 \\
\hline
\end{tabular}

Simulation capability is quantified using the capability criterion used in Kerr et al. [56]. These are repeated here for clarity: Coefficient of determination $\left(R^{2}\right.$ is a number that indicates how well data fit a regression line, with an ideal value of one), root mean square error ( $E_{R M S}$ is a measure of the magnitude of error, with an ideal value of zero), mean error $(\bar{E})$, slope of the best fit line $(\mathrm{m}$, with an ideal value of one), mean normalized bias ( $B_{m n}$ is a measure of the model's magnitude of overprediction or underprediction normalized to the observed value, with an ideal value of zero):

$$
B_{m n}=\frac{\frac{1}{N} \sum_{i=1}^{N} E_{i}}{\frac{1}{N} \sum_{i}^{N}\left|O_{i}\right|}
$$

where $O$ is the observed value, $E$ is the error in terms of simulated minus observed and $N$ is the number of data points.

Scatter index (SI), which is the standard deviation normalized by the mean observed value, with an ideal value of zero):

$$
S I=\sqrt{\frac{\frac{1}{N} \sum_{i=1}^{N}\left(E_{i}-\bar{E}\right)^{2}}{\frac{1}{N} \sum_{i=1}^{N}\left|O_{i}\right|}}
$$

Mean absolute error $(M A E)$, and mean normalized error $\left(E_{N O R M}\right.$, which is the mean error normalized by the mean observed value, with an ideal value of zero):

$$
E_{\text {NORM }}=\sqrt{\frac{\frac{1}{N} \sum_{i=1}^{N}\left(E_{i}\right)^{2}}{\frac{1}{N} \sum_{i=1}^{N}\left(O_{i}\right)^{2}}} .
$$


Throughout the simulations, some of the HWM's locations are predicted to be dry, although this varies from case to case. In the statistical analyses of HWMs, only wet locations predicted by simulations are considered [56]. Note that the HWM points are distributed in Louisiana and Texas coasts, but most of the points are in Louisiana on the east side of Rita's landfall location.

\section{Results and Discussion}

To understand the storm surge generation and propagation of a hurricane, relevant meteorological forcing used in ADCIRC+SWAN must be analyzed first. The OWI model is used here as the default meteorological forcing source, as in some of the previous studies [56,65]. Another popular wind field source is the Best track wind data ingested into the GAHM model. Comparison of wind fields and storm surges produced by using the Best track in GAHM against those of OWI are discussed in the following subsection. Comparison of wind fields and storm surges produced using WRF and advisory forecasts in GAHM against those using OWI are discussed in the subsequent subsections.

\subsection{Comparison of Storm Surge Hindcasts Using OWI and Best Track Ingested in GAHM}

Wind fields from OWI and from Best track ingested in GAHM produce distinctive patterns as shown in Figure 2a,b (maximum wind fields created using OWI and Best track in the GAHM model). The hurricane actual track line is shown on all color plots. These plots clearly illustrate that the right sector of Hurricane Rita had higher wind velocity than the left one, as expected. However, the wind field from Best track in the GAHM is much stronger than that of OWI. The OWI has a noticeably weaker wind field near landfall area than that of Best track in GAHM. Far away from the landfall area, the wind field gradually decays in OWI, whereas the wind field from Best track in GAHM dies off more quickly. These contrasting representations can be observed from Figure 2c,d, which show the wind vectors at 8:30 a.m. on 24 September of 2005. The asymmetry of wind from the Best track in GAHM is not as pronounced as that of OWI.

Unique geographical features around the landfall of Hurricane Rita produce the distinctive hindcast of water elevation and velocity. Water is pushed against the shoreline near Pecan Island (see Figure $1 \mathrm{~b}$ ) to cause about $5 \mathrm{~m}$ surge at the right/east of landfall, while water at the left/west side could slide past the coast, near the Galveston area, very easily, causing not more than $3 \mathrm{~m}$ surge there, as reported in [65]. Figure 2e,f shows water elevations and velocity vectors at 8:30 a.m. on 24 September of 2005 obtained using OWI and Best track in GAHM wind fields, respectively.

A closer inspection shows that Best track in GAHM (Figure 2f) causes peak surge in a more narrow geographical area mostly on the right side of the track, and its southward velocity vectors are weaker than those of OWI (Figure 2e). Figure $2 g$ displays maximum water elevation for OWI, which inundates a broader coastal area from Louisiana to Texas. Figure $2 \mathrm{~h}$, on the other hand, shows maximum water elevation from Best track in GAHM (while similar to that of OWI), more localized near the landfall area. The maximum water velocities are shown in Figure 2i,j. The maximum surge velocity is more pronounced and localized for the Best track in GAHM than OWI, which is consistent with the former's narrower and stronger wind field (Figure 2b).

Both OWI and Best track in GAHM seem to be good candidates to be the default case for inter-model comparison purposes, at least qualitatively. However, it was found that OWI was a better choice after results were quantitatively compared against buoy tide gages and high water marks, as is discussed in the subsequent subsections. Therefore, all pertinent comparisons are eventually done against OWI hindcast results. 


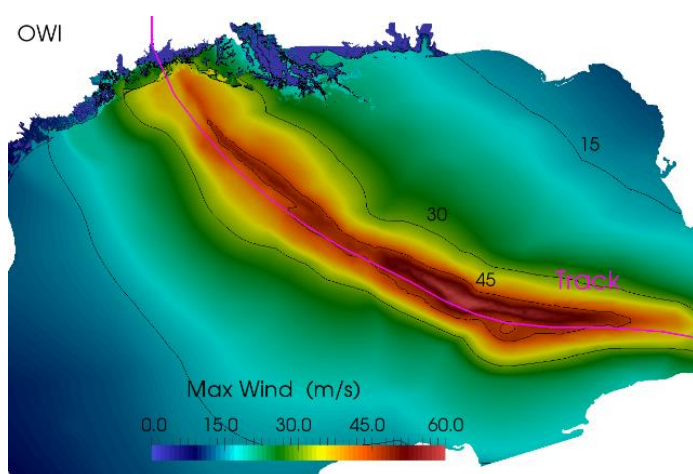

(a)

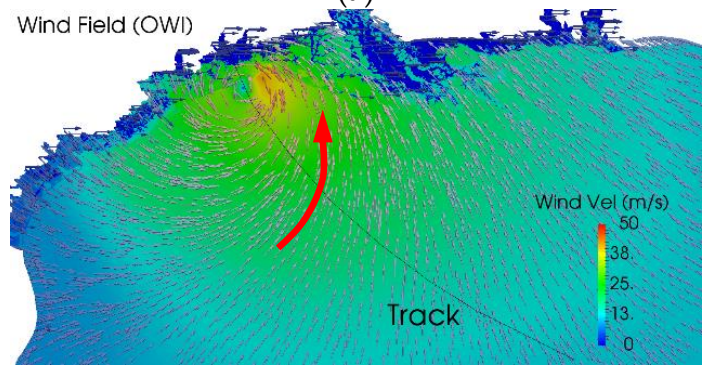

(c)

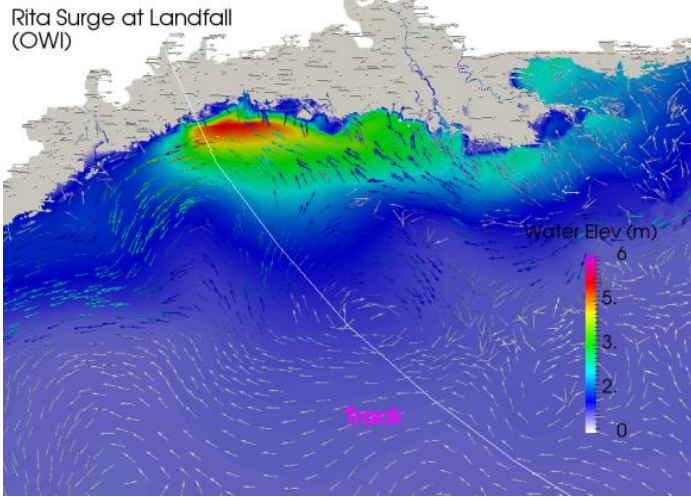

(e)

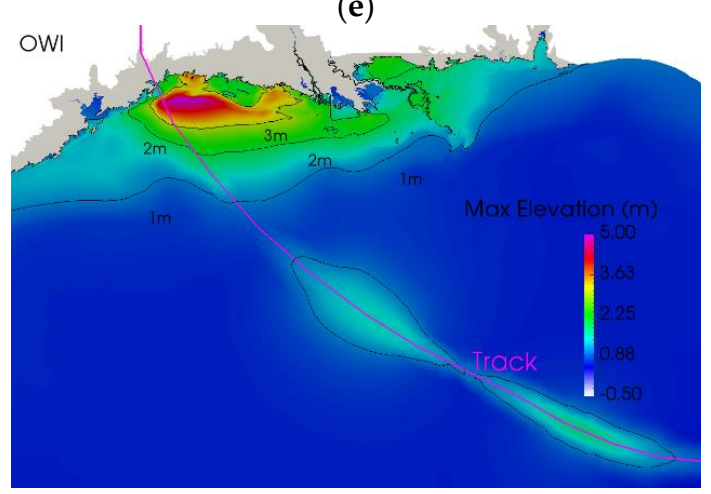

(g)

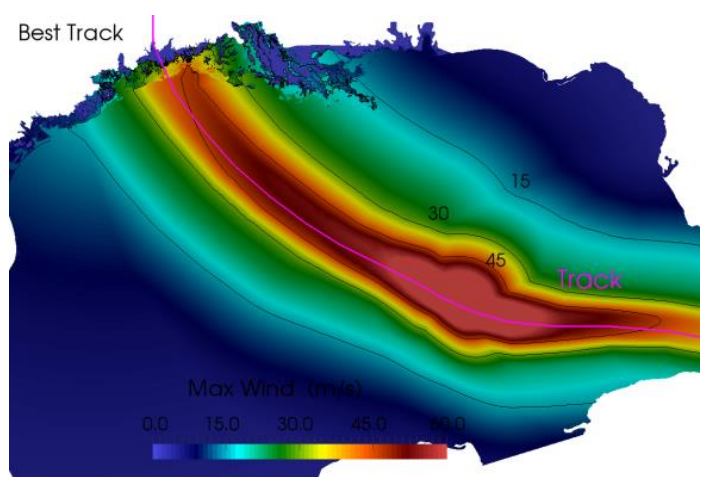

(b)

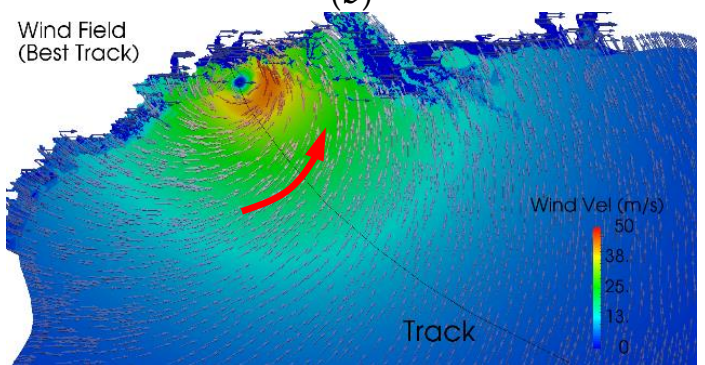

(d)

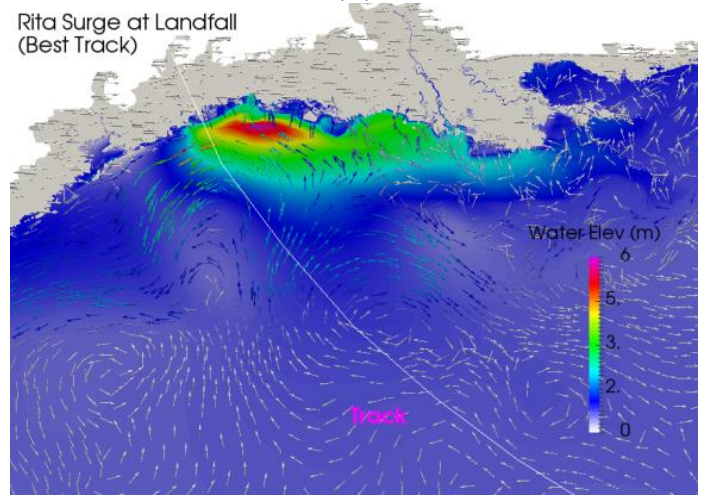

(f)

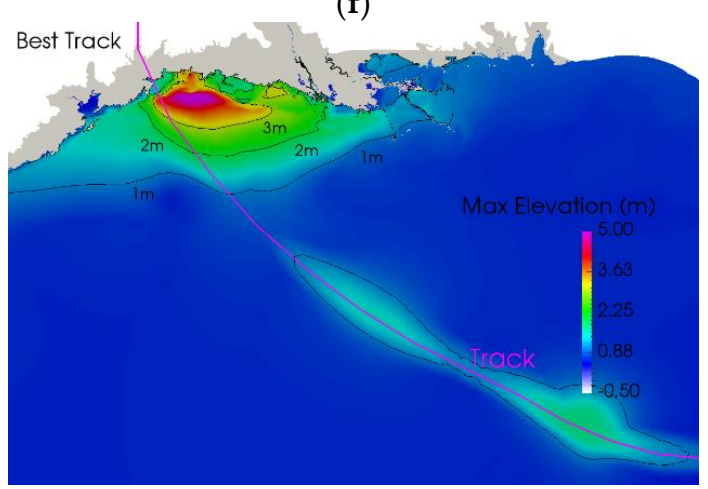

(h)

Figure 2. Cont. 


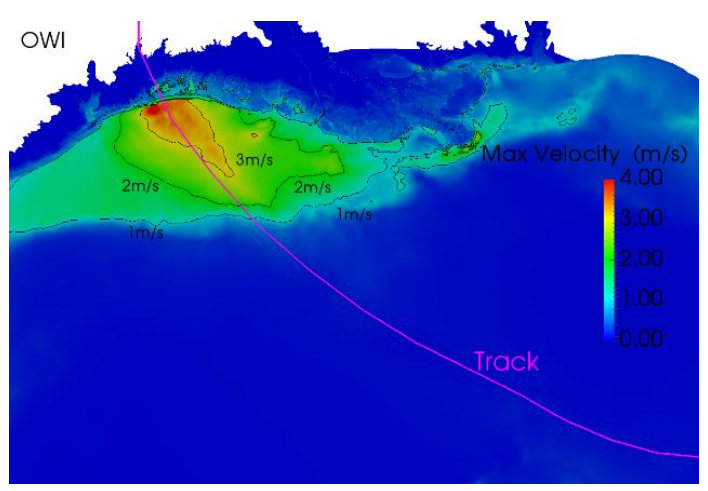

(i)

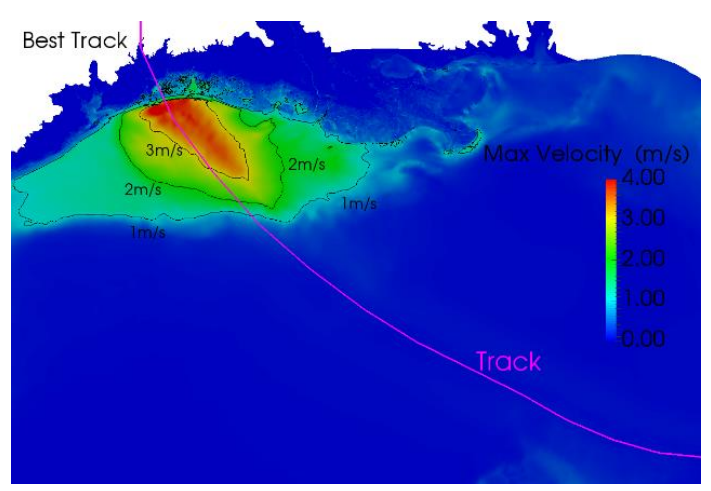

(j)

Figure 2. Wind field and storm surge hindcast results using Oceanweather Inc. (OWI) (a,c,e,g,i) and Best track in Generalized Asymmetric Holland Model (GAHM) - NWS = 20 option $(\mathbf{b}, \mathbf{d}, \mathbf{f}, \mathbf{h}, \mathbf{j}),(\mathbf{a}, \mathbf{b})$ maximum wind track; (c,d) Wind vector at 8:30 a.m., 24 September of 2005; (e,f) Water elevation and velocity vector at 8:30 a.m., 24 September of 2005; (g,h) maximum water elevation; (i,j) maximum water velocity.

\subsection{Storm Surges Using WRF Forecasts}

Five WRF simulations are performed to examine the sensitivity of 'forecasted' storm intensities and tracks to their starting or initialization times. The first simulation (WRF Run 1) was initialized at 09/22/2005 0000 UTC, approximately $56 \mathrm{~h}$ before the landfall. The initialization times of subsequent simulations were decreased by $12 \mathrm{~h}$. Details of simulation initialization times are summarized in Table 3. All simulations were stopped at 1200 UTC on 25 September of 2005. WRF outputs were processed to prepare the wind fields for ADCIRC+SWAN. For the duration from 09/18/2005 0000 UTC to WRF initialization times, the OWI wind fields were used in ADCIRC+SWAN to produce the hindcast of Rita storm surges and to create hot start files. These hot start files were then used in ADCIRC+SWAN to restart the simulation with WRF wind fields to forecast the surge. Note that wind fields from the Best track in GAHM were originally used for the hindcast durations (when the storm was still far from shore) and the influence of wind fields in the middle of the ocean on coastal surges occurring days later was not significant. Since OWI wind fields are observation-based, considered more reliable, and should be available for hindcast periods, a decision was made to use OWI wind fields instead of those of Best track in GAHM for all 'forecast' studies performed here.

Table 3. Description of WRF runs and initialization times for surge forecasts.

\begin{tabular}{ccc}
\hline Simulation Number & Initialization Time (UTC) & Hours before Landfall \\
\hline WRF Run 1 & $9 / 22 / 20050000$ & 56 \\
WRF Run 2 & $9 / 22 / 20051200$ & 44 \\
WRF Run 3 & $9 / 23 / 20050000$ & 32 \\
WRF Run 4 & $9 / 23 / 20051200$ & 20 \\
WRF Run 5 & $9 / 24 / 20050000$ & 8 \\
\hline
\end{tabular}

\subsubsection{Comparison of Wind Fields from WRF and OWI}

The hybrid OWI and WRF maximum wind fields are displayed in Figure 3. WRF maximum wind fields are noticeably wider and weaker than that of OWI (either Figure 2a or Figure 3f) or of Best track in GAHM (Figure 2b). However, WRF hurricane predictions are reasonably accurate and generally go over the track line, although the exact curvature of the track is missing from all WRF wind fields. A careful inspection of Figure $3 a-c$ reveals that the landfall locations of some WRF predicted hurricanes are slightly off as well. For example, WRF Run 3 lands a bit west of the actual landfall location, and its overall wind field is stronger than those of other WRF runs. Although this is a small departure from the actual landfall location, it makes an important difference in surge generation and 
propagation characteristics, as discussed later. All WRF results predicted reduced peak wind speed before landfall, correctly indicating the weakened status of Rita at that point, which is obvious in the OWI wind field as well. The choice of WRF physics setup plays an important role in the accuracy of wind field prediction.

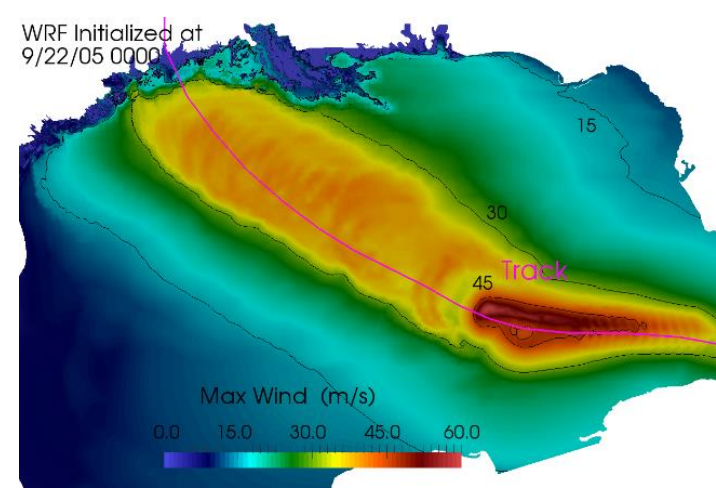

(a)

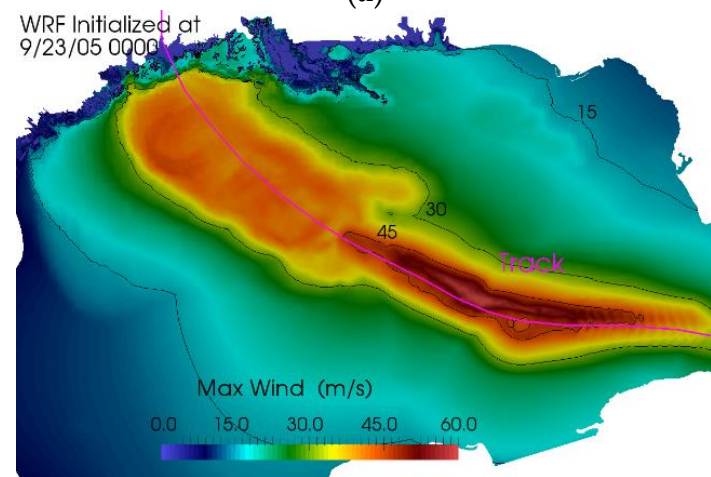

(c)

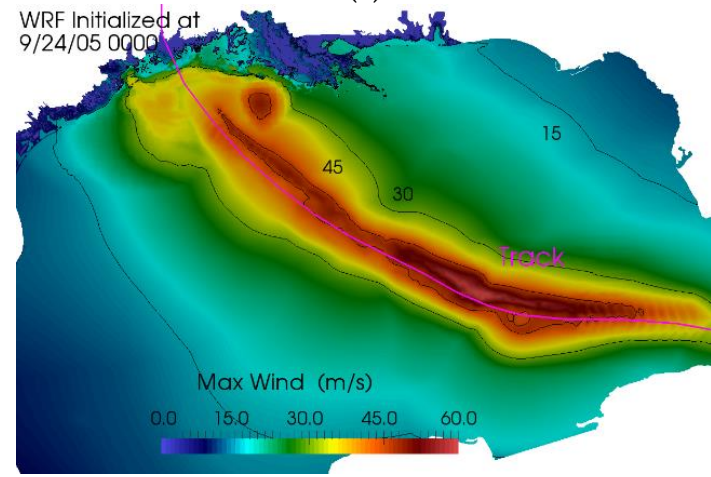

(e)

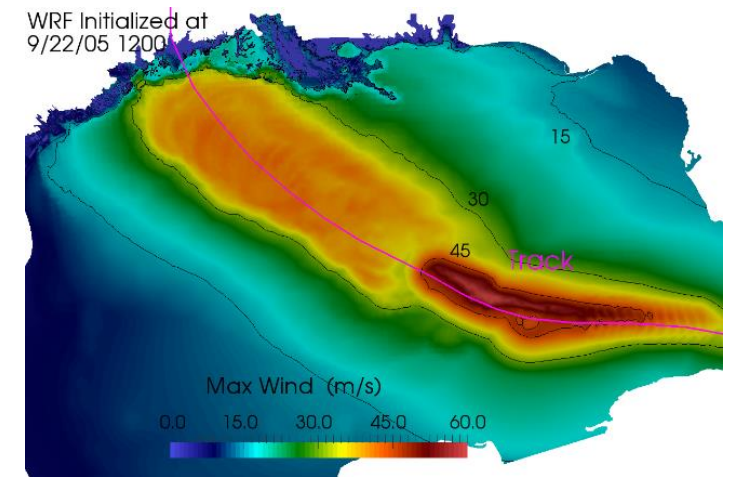

(b)

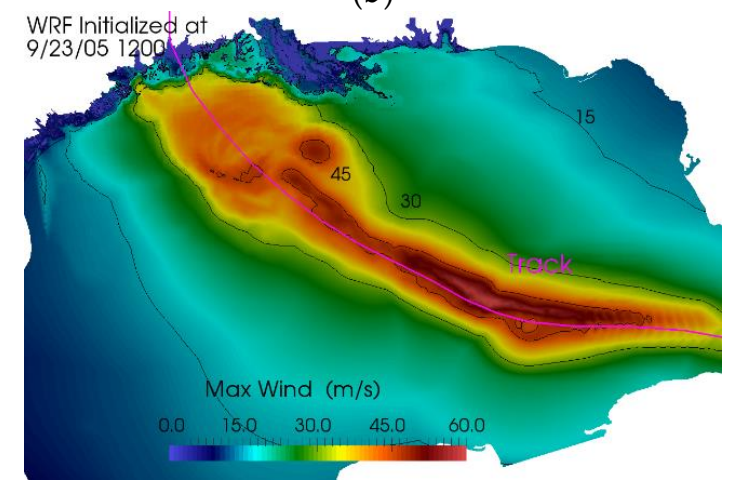

(d)

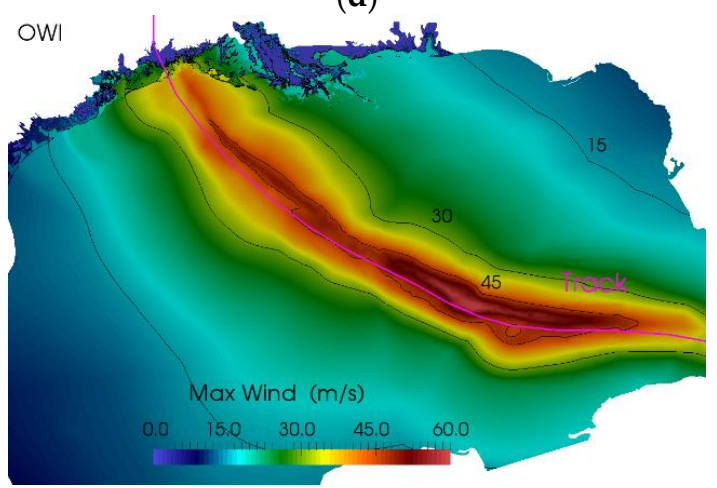

(f)

Figure 3. Rita maximum wind track plots using wind fields from WRF and OWI models. (a) WRF Run 1, (b) WRF Run 2, (c) WRF Run 3, (d) WRF Run 4, (e) WRF Run 5, and (f) OWI.

\subsubsection{Comparison of Storm Surges Using WRF and OWI Wind Fields}

Figure 4 shows the maximum water elevation color plots generated from different storm surge forecasts using the WRF and OWI wind fields, as shown in Figure 3. The water surface elevations were significantly lower for all WRF cases (Figure 4a-e) than those of OWI (Figure 4f). However, the extent of inundation was as broad or even greater than the extent for OWI. The finding is somewhat expected, given that WRF wind fields are wider. Among all WRF runs, Run 3 seems to generate a maximum water surface elevation closest to that of the OWI. Figure 5 shows the maximum water velocity color plots produced from different storm surge runs using the WRF and OWI wind fields, as shown in 
Figure 3. The velocity plots show significantly weaker maximum water velocity fields from WRF runs compared with OWI.

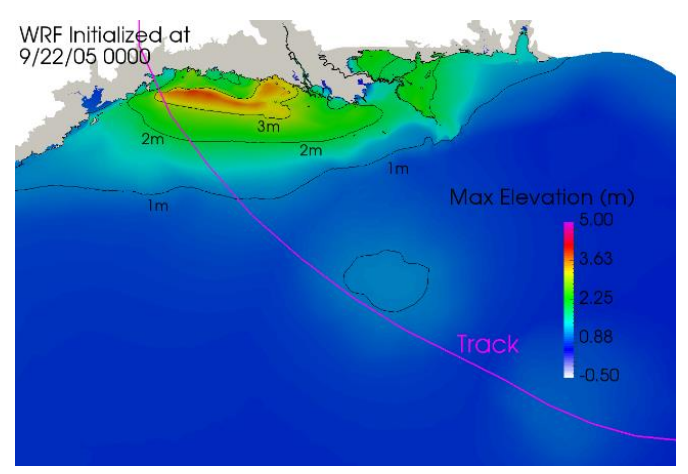

(a)

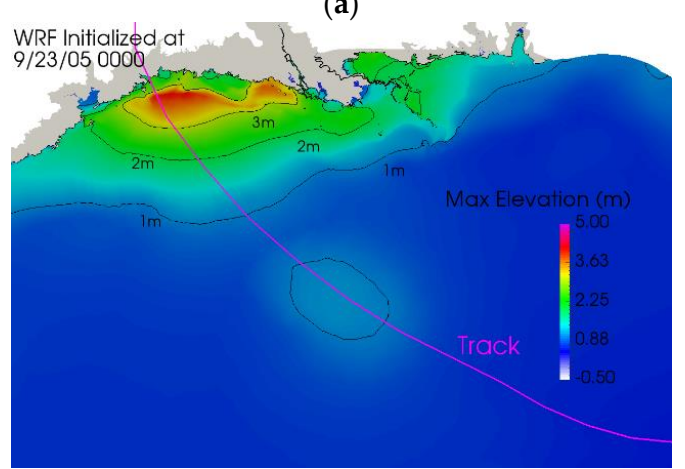

(c)

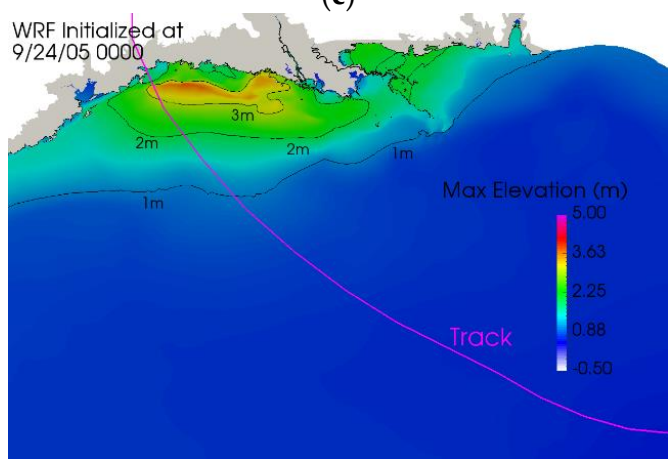

(e)

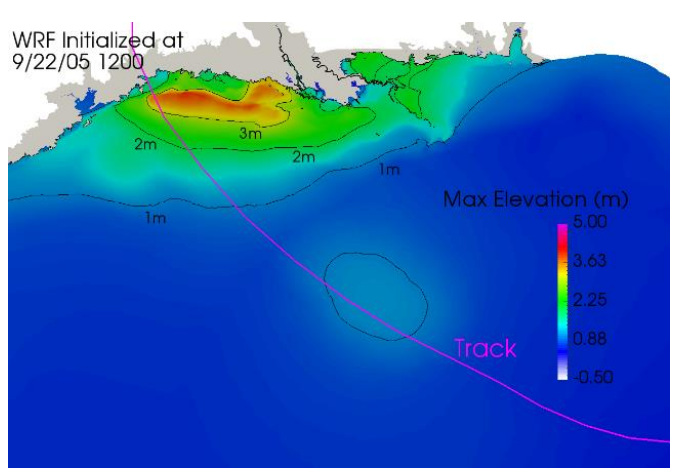

(b)

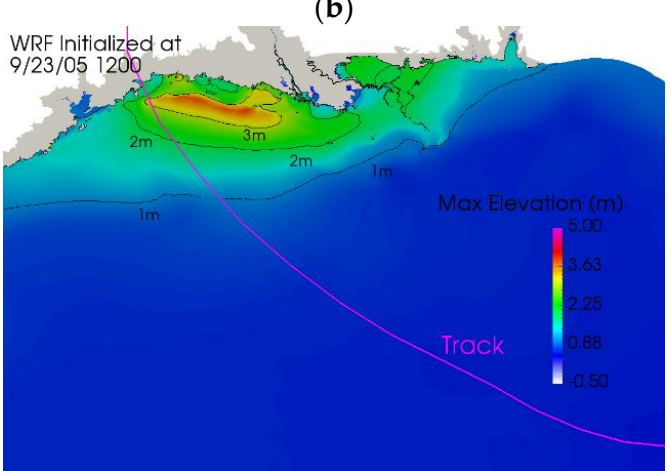

(d)

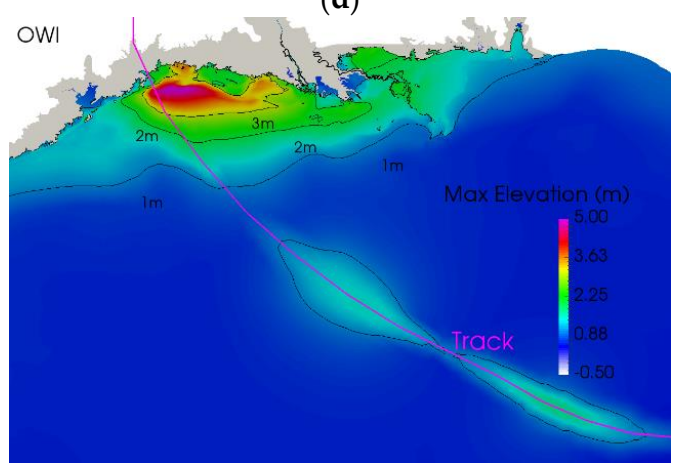

(f)

Figure 4. Rita maximum water elevation from ADvanced CIRCulation + Simulating Waves Nearshore (ADCIRC+SWAN) simulation results using wind fields from WRF and OWI models. (a) WRF Run 1, (b) WRF Run 2, (c) WRF Run 3, (d) WRF Run 4, (e) WRF Run 5, and (f) OWI.

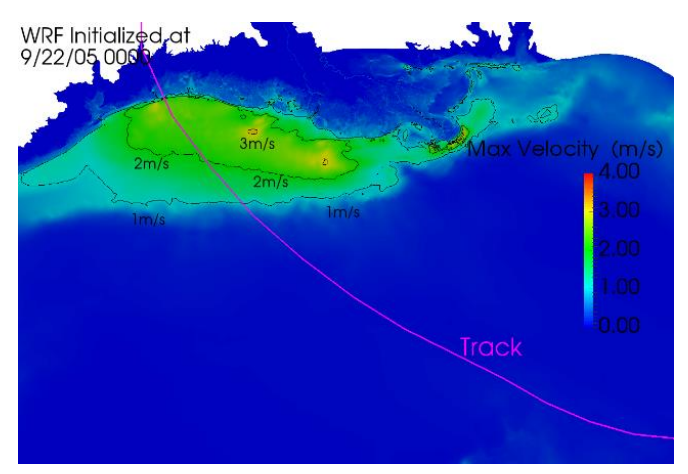

(a)

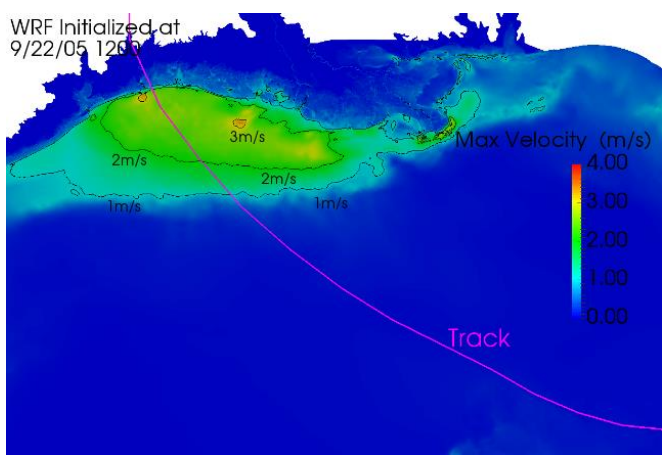

(b)

Figure 5. Cont. 


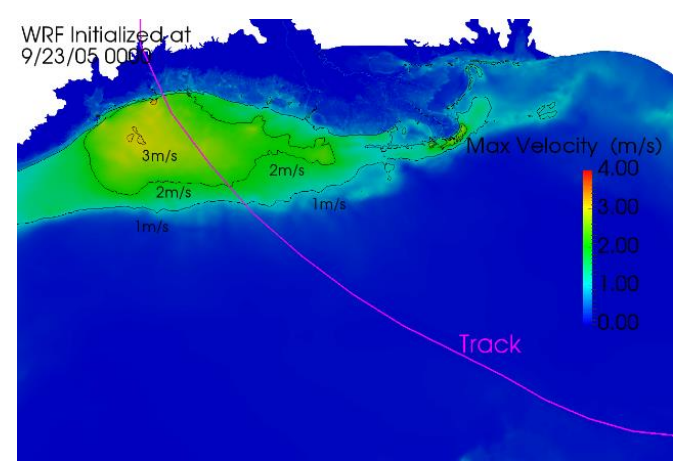

(c)

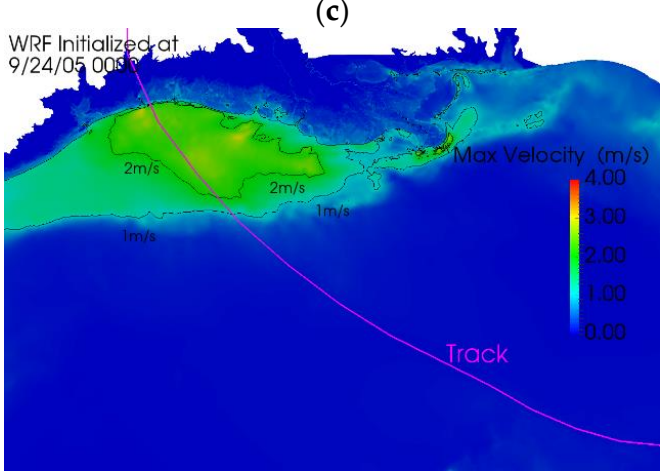

(e)

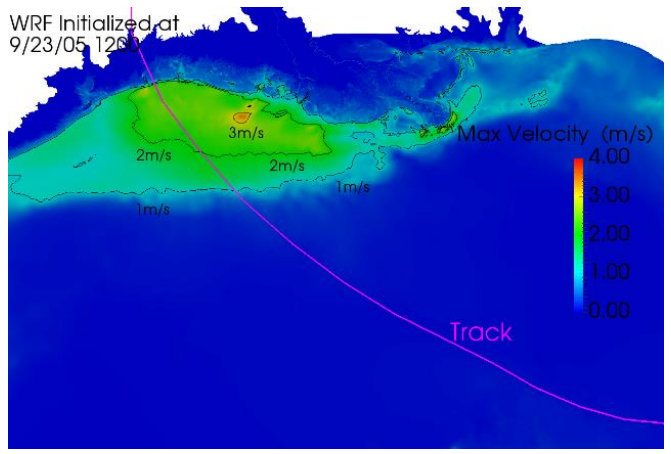

(d)

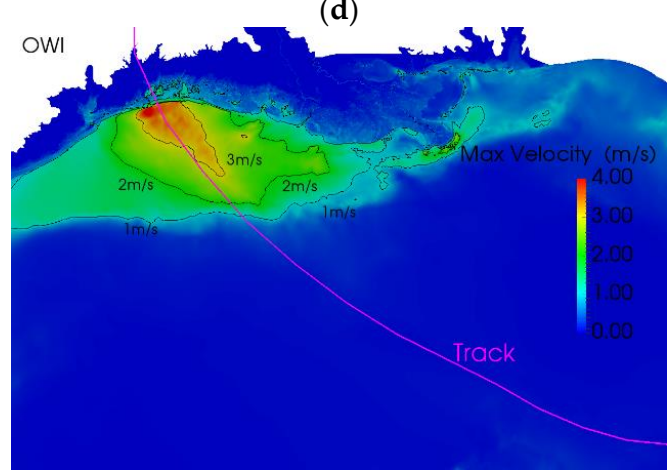

(f)

Figure 5. Rita maximum water velocity from ADCIRC+SWAN simulation results using wind fields from WRF and OWI models. (a) WRF Run 1, (b) WRF Run 2, (c) WRF Run 3, (d) WRF Run 4, (e) WRF Run 5, and (f) OWI.

\subsubsection{Quantitative Differences between the WRF Forecast and OWI Hindcast}

To quantify differences, maximum wind, maximum water elevation and velocity of WRF runs were subtracted from those of the OWI run. For brevity, differences only between OWI and WRF Run 3 results are reported here in Figure 6 since it (i.e., WRF Run 3) appeared to be the best WRF case. Figure 6a shows that the WRF Run 3 maximum wind speed near the coastal regions was weaker by about $10 \mathrm{~m} / \mathrm{s}$ (see inside purple oval) than that of OWI, which can be qualitatively verified by comparing Figure $3 c, f$. Otherwise, Figure 6a shows that WRF wind was stronger, at some places by $20 \mathrm{~m} / \mathrm{s}$, than that of OWI on the left side of the track. On the right side of the track, the OWI wind was slightly stronger near the track and at some scattered places. Although WRF wind vectors at 8:30 a.m., 24 September of 2005 were stronger near landfall, as seen in Figure 6b, the presence of land weakened its wind very quickly, leading to the situation described in Figure 6a (purple oval). Most likely this weakening is directly related to the physics and land resistance setup used in WRF. Overall, the WRF wind vortex is more symmetric than that of OWI.

The maximum water elevation generated by the OWI wind field was higher by $1 \mathrm{~m}$ than that of WRF Run 3 on the right/eastside of the track, as seen in Figure 6c. On the east side of the Rita landfall location near Pecan Island, water was pushed against the shoreline, more so for the OWI wind field that is asymmetric in nature and stronger near shoreline. On the other hand, water on the left/westside of the landfall location flowed southward uninterrupted, especially for OWI due its weaker wind field there. WRF Run 3 generated about $1 \mathrm{~m}$ higher water elevation on the west side of the track. As seen in Figure $6 \mathrm{~d}$, the maximum water velocity generated by the OWI wind field was consistently higher by $1 \mathrm{~m} / \mathrm{s}$ on the east side of the track, but similarly lower than that of WRF Run 3 on the west side. These findings are consistent with the relevant wind fields. 


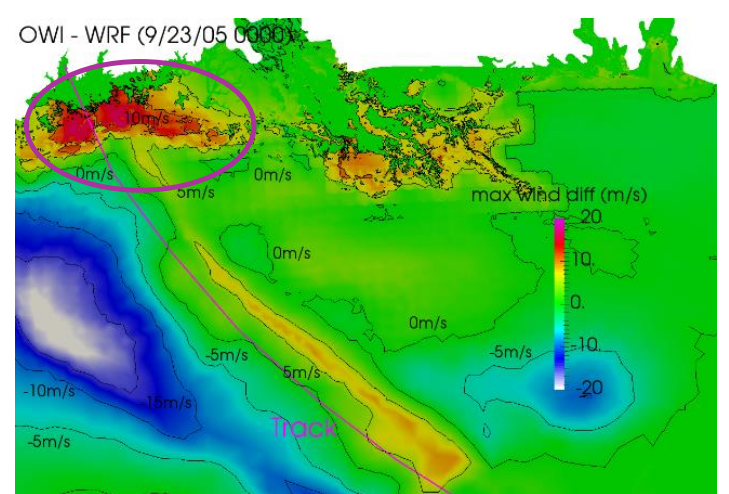

(a)

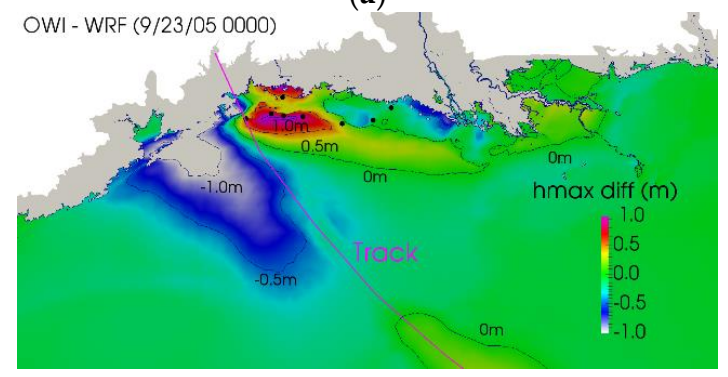

(c)

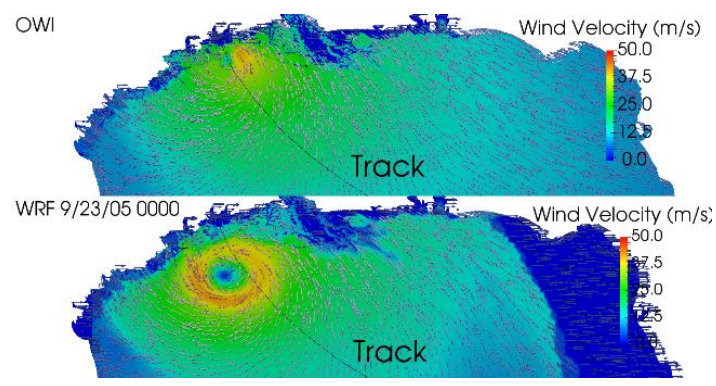

(b)

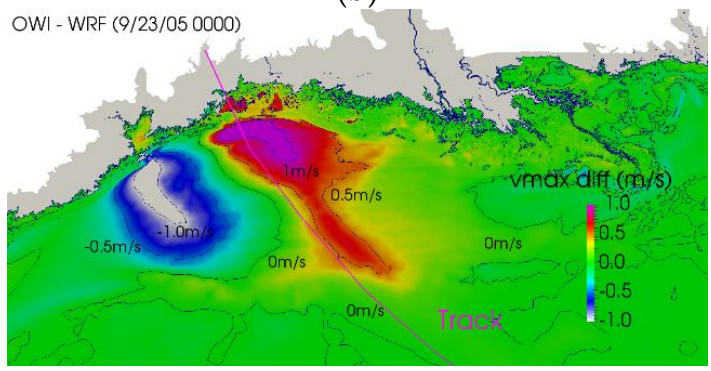

(d)

Figure 6. Differences and contrasts between OWI hindcast and WRF Run 3-initialized at 9/23/05 0000 forecast results of Hurricane Rita storm surges: (a) difference of maximum wind speed, (b) contrast of wind vectors at landfall, (c) difference of maximum water elevation, and (d) difference of water velocity. The black dots are the locations of eight stations listed in Table 2.

\subsubsection{Comparison of Surge Time Series Using WRF, OWI, and Best Track in GAHM Winds}

The ADCIRC+SWAN water level time series were compared to observed water levels at stations (displayed on Figure 1b). Away from landfall at station (J), Figure 7a indicates that OWI simulation accurately predicted the surge propagation, but with an early peak arrival by about $3 \sim 4 \mathrm{~h}$. Kerr et al. [56] indicated a possible error in the hydraulic connectivity in the marsh as the reason. Their study indicated that bottom friction, mesh resolution, and other features may have contributed to the mismatch between simulated results and observed data. The station seemed to be inundated hours before the arrival of the peak, whereas the simulation predicted zero water elevation at the beginning and then a subsequent sudden rise of water. The Best track in GAHM simulation behaved about the same, except for a closer match of the peak with the observed data. The peak arrivals for WRF runs were hastened or delayed by different durations, although the peak magnitudes matched reasonably well with the observed data. Weather Research and Forecasting Run 3 seems to have a delayed arrival of the peak by about $3 \mathrm{~h}$, however. Recall that WRF Run 3 landfall is on the west side of the actual landfall (refer to Figure 4c), i.e., further away from station J. Therefore, a delayed peak arrival was expected for this run.

In the region of landfall, Figure $7 \mathrm{~b}-\mathrm{e}$ at stations (H, I, D, and F), both OWI and Best track in GAHM cases overpredict the water elevation peak by $0.5 \mathrm{~m}$ to $1 \mathrm{~m}$ at most stations, some of which Kerr et al. [56] attributed to improper road resolution. All WRF runs underpredict the peak by $0.25 \mathrm{~m}$ to $1 \mathrm{~m}$ at most stations, probably directly related to their weak wind fields. Expectedly, WRF Run 3 has delayed peak arrivals by about $3 \mathrm{~h}$. Otherwise, WRF Run 3 peak heights are the highest and closest to the observed ones among all WRF runs.

At inland stations (E, C, and G) (Figure 7f-h), both OWI and the Best track in GAHM cases overpredicted the peak water levels with a phase lead by $1 \mathrm{to} 7 \mathrm{~h}$. All WRF runs also overpredicted the water elevation peak, although somewhat less in extent and with some reduced phase lead/delay. The phase lead or delay of WRF runs varied significantly. The Run 3 seemed to have the least amount 
of phase difference from the observation data, which again was due to the distant landfall location from these stations. For station C, WRF Run 3 had a delayed peak arrival by about $3 \sim 4 \mathrm{~h}$, which can be attributed to the station not being directly in its surge generation and propagation path.

Four stations are chosen on the west side of the landfall. Stations K, N, and $\mathrm{O}$ are along the coast, while the station $Q$ is inside the Galveston Bay area (see Figure 1b). As shown in Figure 7i-k, the OWI and Best track in GAHM winds generally overpredict the surge with some phase leads. Modeled surges propagate quickly along the Texas coast uninterrupted and the early arrivals of the peaks at stations $\mathrm{K}, \mathrm{N}$, and O confirm this. The double surge peaks shown by OWI and Best track in GAHM is an interesting feature displayed at both stations $\mathrm{N}$ and $\mathrm{O}$, probably resulting from the transient pattern relevant to those wind fields. WRF winds generally predict slightly lower surge peaks but with some phase leads, similar to those of OWI surges. The double peaks are not visible in WRF surges in stations $\mathrm{N}$ and $\mathrm{O}$. As shown in Figure 7l, the Galveston Bay station, $\mathrm{Q}$, is away from the direct path of surge propagation and all cases generally predict the peak well with few phase differences. Note that station $\mathrm{N}$ had a discontinuity in buoy data for a few hours, and reason is not known to the authors.

Overall, the Best track in the GAHM simulation performed somewhat similarly to those of OWI for these limited number of stations. However, the HWM analysis presented below with 144 observation points reveals that storm surge generation and propagation simulated by Best track in GAHM was not as accurate as those of OWI and WRF forecasts.

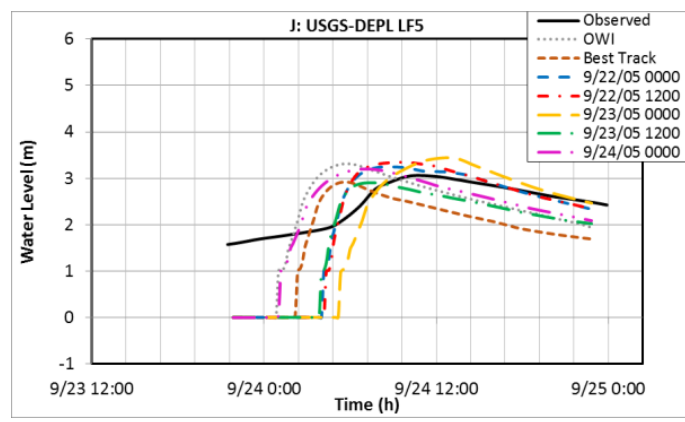

(a)

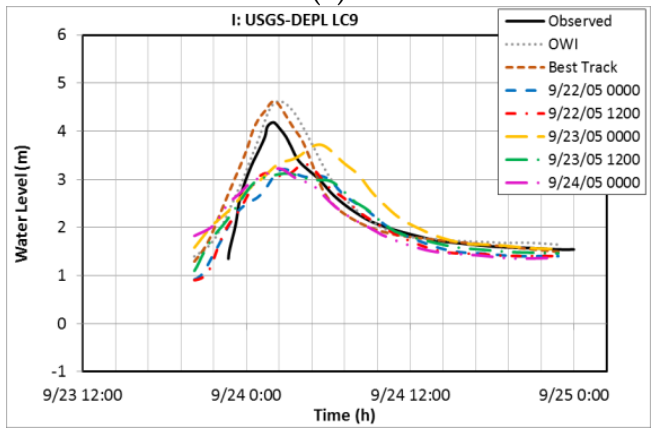

(c)

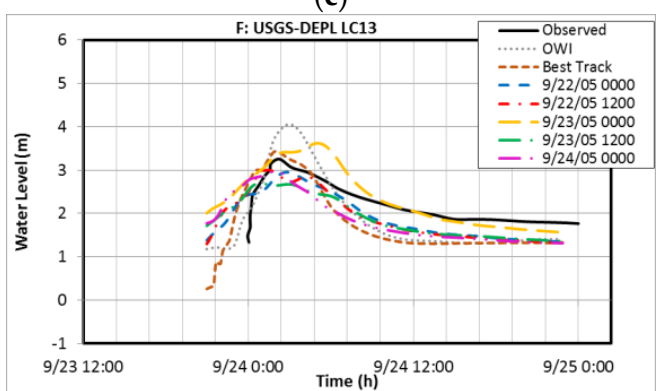

(e)

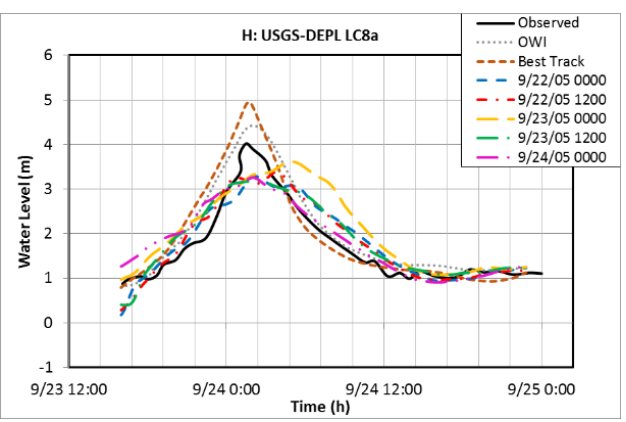

(b)

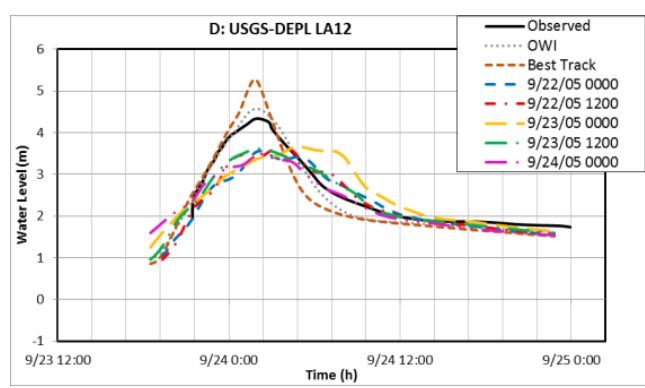

(d)

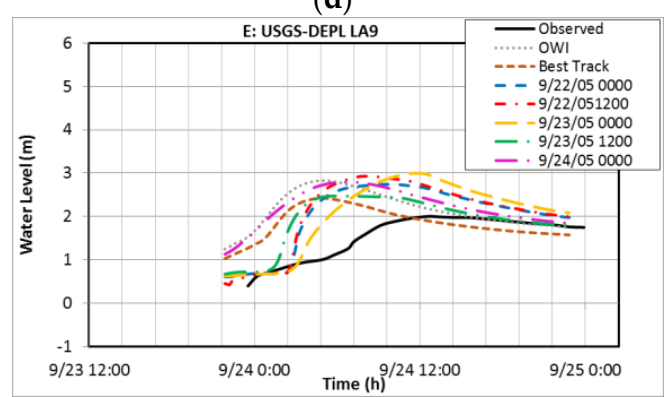

(f)

Figure 7. Cont. 


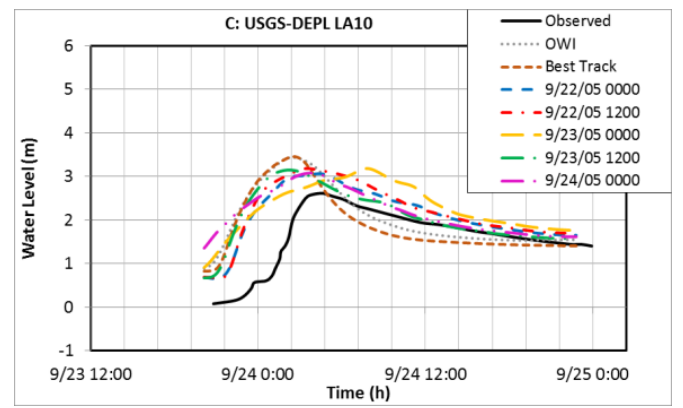

(g)

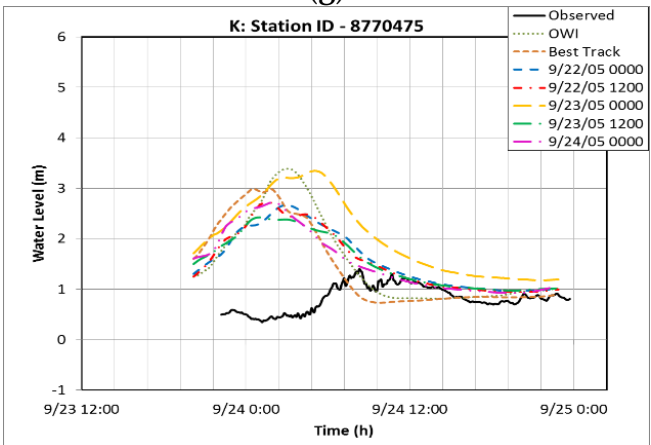

(i)

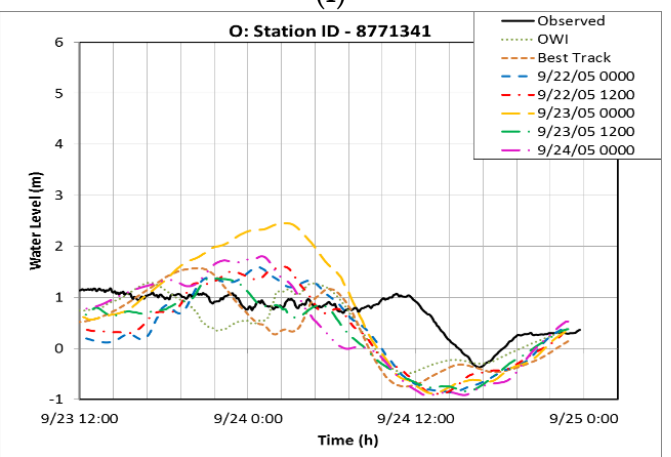

(k)

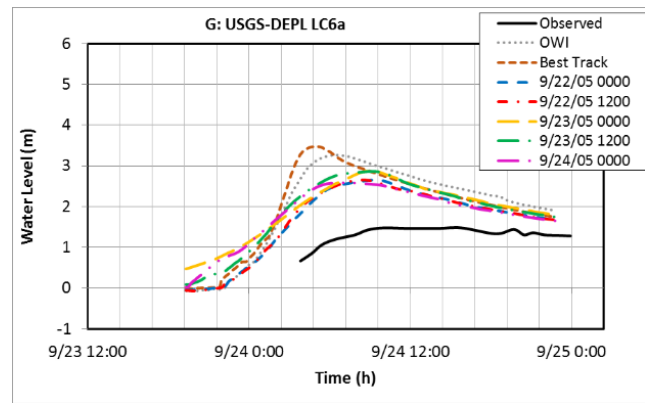

(h)

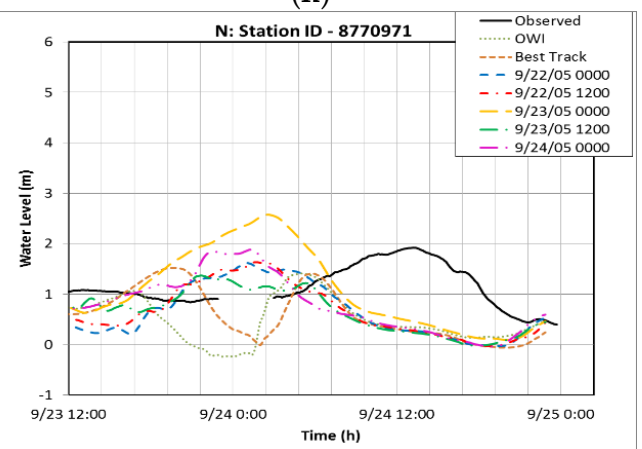

(j)

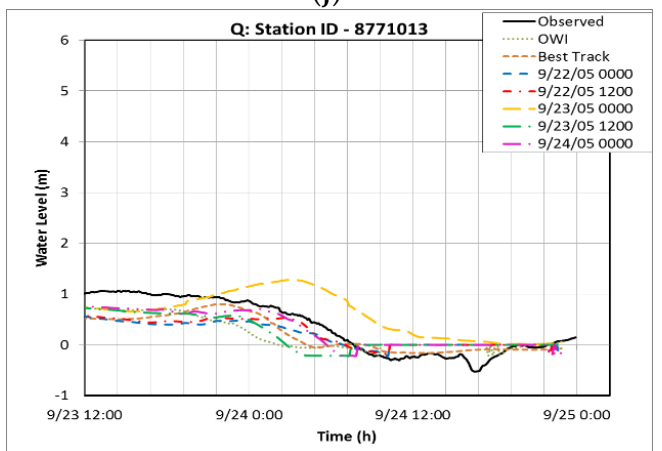

(1)

Figure 7. Effect of wind fields from WRF, OWI, and Best track in GAHM models: Observed and ADCIRC+SWAN modeled significant water level time series at different observation stations during the time of Hurricane Rita (9/22-25/05). (a) J-USGS-DEPL LF5; (b) H-USGS-DEPL LC8a; (c) I-USGS-DEPL LC9; (d) D-USGS-DEPL LA12; (e) F-USGS-DEPL LC13; (f) E-USGS-DEPL LA9; (g) C-USGS-DEPL LA10; (h) G-USGS-DEPL LC6a; (i) K-ID 8770570, Sabine Pass North, TX; (j) N-ID 8770971, Rollover Pass, TX; (k) O-ID 8771341, Galveston Bay Entrance, North Jetty, TX; (l) Q-ID 8771013, Eagle Point, Galveston Bay, TX.

\subsubsection{Comparison of High Water Mark Using WRF, OWI, and Best Track in GAHM Winds}

The maximum water elevations were compared for each of the simulations to measured high water marks (HWMs) [64] in Figure 8. Just as in Kerr et al. [56], only wet stations were used for all simulated HWM analysis. The summarized statistics are given in Table 4. Kerr et al. [56] obtained an $R^{2}$ value of 0.663 using the lumped-explicit solver option in the ADCIRC+SWAN model to hindcast Rita's storm surge using the OWI wind field. The present study, which used the semi-implicit solver option of ADCIRC+SWAN, obtained 0.704 for the OWI model, as shown in Table 4. All WRF runs had higher correlation coefficients, lower mean errors, Biases, SIs and MAEs than those of OWI. The number of dry locations was either 9 or 10 for WRF runs, whereas the OWI run had seven dry locations. With 23 dry locations (a large number) the Best track in GAHM case had the lowest correlation coefficient. As caveat, the correlation coefficient alone may be a misleading criterion to judge the HWM comparison [65]. A simulation may produce a lower inundation extent, yet score a 
high correlation coefficient since dry locations are typically ignored from the statistics. The case was different here, however. It was remarkable that all WRF cases had high correlation coefficients, yet most locations were wet. The comparison against the orange parity line shows that low surge HWMs were overpredicted and high surge HWMs were underpredicted by all WRF cases. High Water Marks of both OWI and the Best track in GAHM were closer to the parity line, although both overpredicted the surge in most wet locations. Considering only the wet nodes, the Best track in GAHM has lower or comparable values of root mean square error $\left(E_{R M S}\right)$, mean error $(\bar{E})$, mean normalized bias $\left(B_{M N}\right)$, mean absolute error $(M A E)$, and mean normalized error $\left(E_{N O R M}\right)$ than OWI. However, the scatter indices ( $\sigma$ and SI) of Best track in GAHM are larger than those of OWI. On the contrary, all error and scatter indices for WRF Run 3 are less than those of OWI.

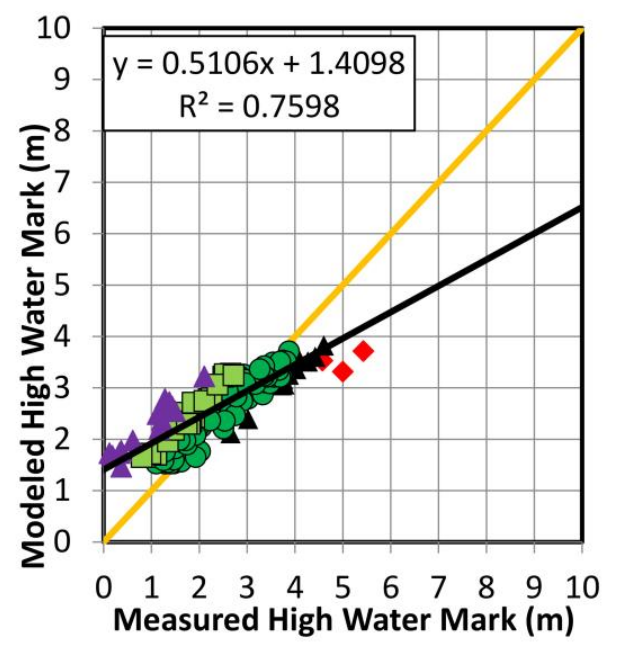

(a)

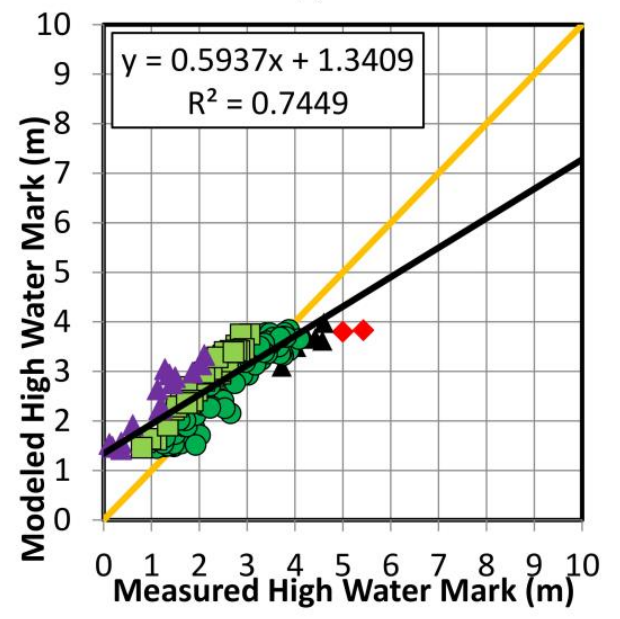

(c)

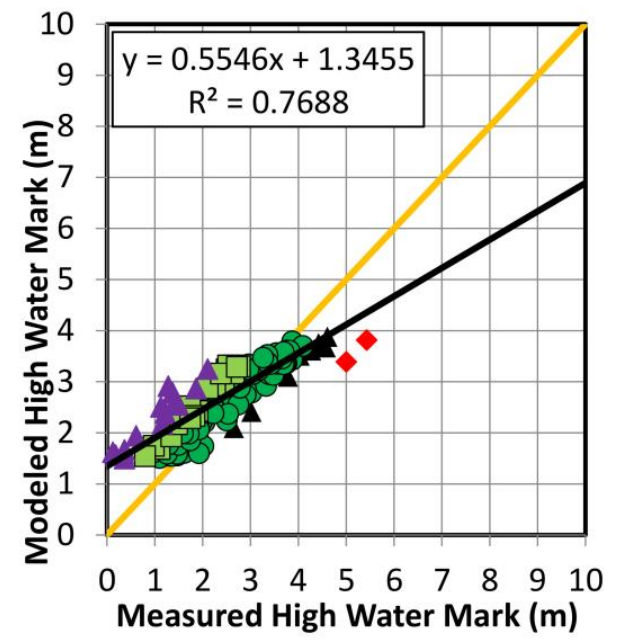

(b)

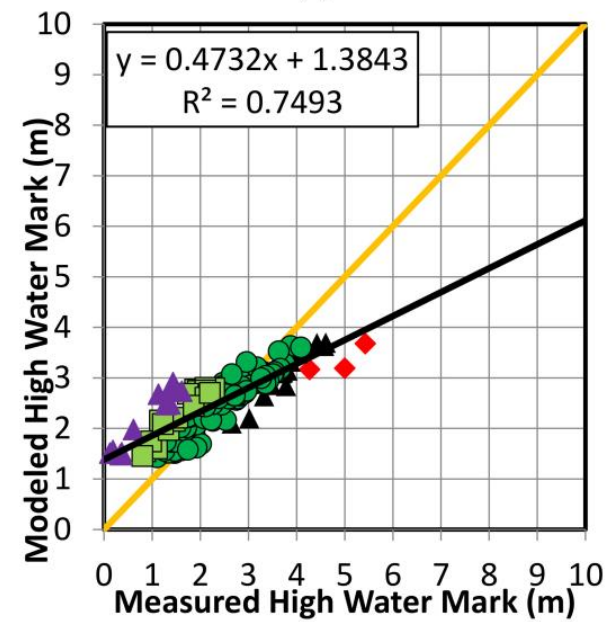

(d)

Figure 8. Cont. 


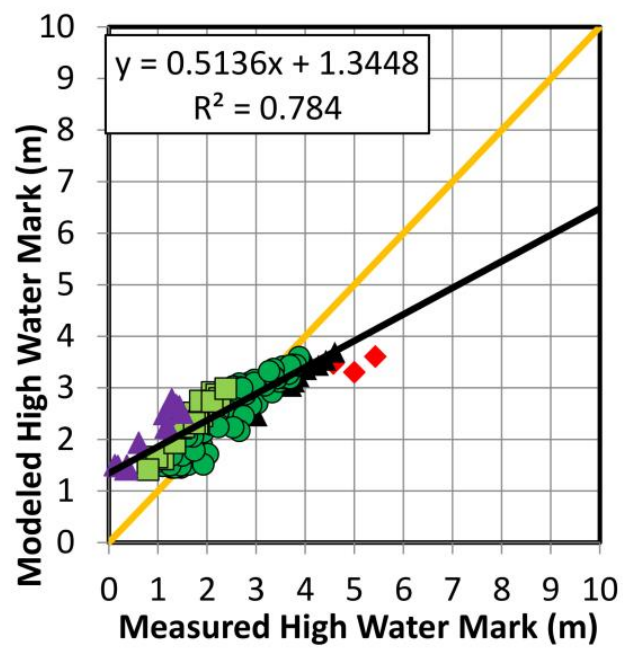

(e)

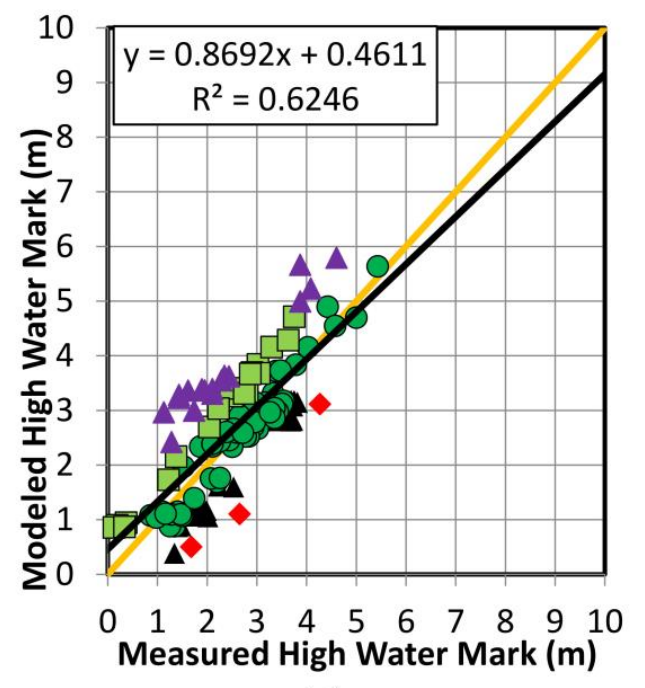

(g)

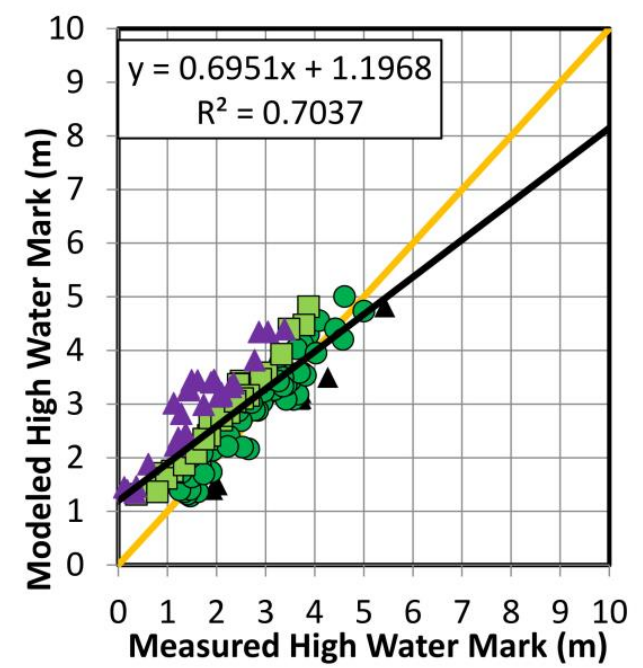

(f)

Figure 8. Scatter plots of Rita high water marks (HWM's) from ADCIRC+SWAN simulations using wind fields from WRF, OWI, and Best track in GAHM models. (a) WRF Run 1, (b) WRF Run 2, (c) WRF Run 3, (d) WRF Run 4, (e) WRF Run 50, (f) OWI, and (g) Best track in GAHM. Red diamond and black triangles indicate underprediction by the model; purple triangles and light green squares indicate overprediction. Dark green circles indicate a match within $0.5 \mathrm{~m}$. The black line represents the best fit lines. The orange line is the parity.

Table 4. HWM error statistics for Rita surge forecast and hindcast using wind fields from WRF, OWI, and Best Track in GAHM.

\begin{tabular}{|c|c|c|c|c|c|c|c|c|c|c|}
\hline Case & $R^{2}$ & $E_{R M S}(m)$ & $E(m)$ & $\mathrm{B}_{\mathrm{MN}}(-)$ & $\sigma(\mathrm{m})$ & SI (-) & MAE (m) & $\mathrm{E}_{\text {NORM }}{ }^{(-)}$ & Dry & Wet \\
\hline WRF Run 1 & 0.760 & 0.459 & 0.256 & 0.108 & 0.629 & 0.407 & 0.534 & 0.068 & 10 & 134 \\
\hline WRF Run 2 & 0.769 & 0.443 & 0.295 & 0.125 & 0.598 & 0.387 & 0.520 & 0.068 & 10 & 134 \\
\hline WRF Run 3 & 0.745 & 0.515 & 0.391 & 0.166 & 0.604 & 0.392 & 0.564 & 0.077 & 9 & 135 \\
\hline WRF Run 4 & 0.749 & 0.470 & 0.153 & 0.065 & 0.671 & 0.435 & 0.525 & 0.070 & 9 & 135 \\
\hline WRF Run 5 & 0.784 & 0.435 & 0.208 & 0.088 & 0.628 & 0.408 & 0.511 & 0.065 & 9 & 135 \\
\hline OWI & 0.704 & 0.598 & 0.480 & 0.203 & 0.609 & 0.394 & 0.616 & 0.088 & 7 & 137 \\
\hline Best Track in GAHM & 0.625 & 0.591 & 0.138 & 0.056 & 0.759 & 0.480 & 0.625 & 0.081 & 23 & 121 \\
\hline
\end{tabular}




\subsection{Storm Surges Using Archived Forecast Advisories}

Rita storm surge 'forecasts' were performed using five archived advisories ingested in the GAHM wind model to examine the sensitivity of advisories in storm surge generation and propagation. These advisories were issued during the actual event and are archived in the database of National Hurricane Center. Advisory wind fields ingested in the GAHM are typically used in the ADCIRC+SWAN model to predict hurricane storm surges during an impending event. The first simulation (Adv Run 1) was initialized at 09/22/2005 0300 UTC, approximately $53 \mathrm{~h}$ before the landfall. The initialization times of subsequent simulations were decreased by $12 \mathrm{~h}$. Details of simulation initialization times are summarized in Table 5. All simulations were stopped at 1200 UTC on 25 September of 2005. For the duration from 09/18/2005 0000 UTC to advisory run initialization times, wind fields of OWI were used in ADCIRC+SWAN to simulate the storm surge from Rita. Hot start files were created after these runs, which were used in ADCIRC+SWAN to restart the simulation with wind fields created from advisories in GAHM.

Table 5. Description of Rita advisory runs and initialization times for surge forecasts.

\begin{tabular}{cccc}
\hline Simulation Number & Advisory Identification & Initialization Time (UTC) & Hours before Landfall \\
\hline Adv Run 1 & Advisory 18 & $9 / 22 / 20050300$ & 53 \\
Adv Run 2 & Advisory 20 & $9 / 22 / 20051500$ & 41 \\
Adv Run 3 & Advisory 22 & $9 / 23 / 20050300$ & 29 \\
Adv Run 4 & Advisory 24 & $9 / 23 / 20051500$ & 17 \\
Adv Run 5 & Advisory 26 & $9 / 24 / 20050300$ & 5 \\
\hline
\end{tabular}

\subsubsection{Comparison of Wind Fields from Advisories in GAHM and OWI}

The hybrid OWI and Advisory maximum wind fields are displayed in Figure 9. Advisory wind fields were similar to that of the Best track in GAHM (i.e., Figure 2b), but noticeably stronger and narrower than that of OWI. Advisory 18 (Adv Run 1), the earliest advisory used in the present study, incorrectly predicted landfall south of Galveston area. The later advisories predict the track and curvature reasonably well. Except for the Adv Run 3, all advisories predicted reduced peak wind speed before the hurricane landfall, correctly indicating the weakened status of Rita before landfall.

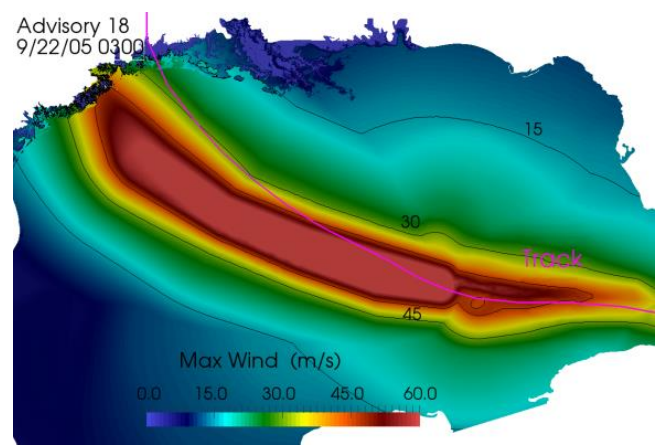

(a)

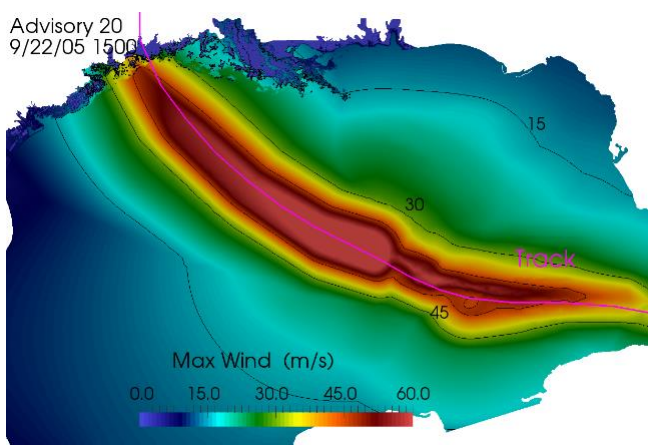

(b)

Figure 9. Cont. 


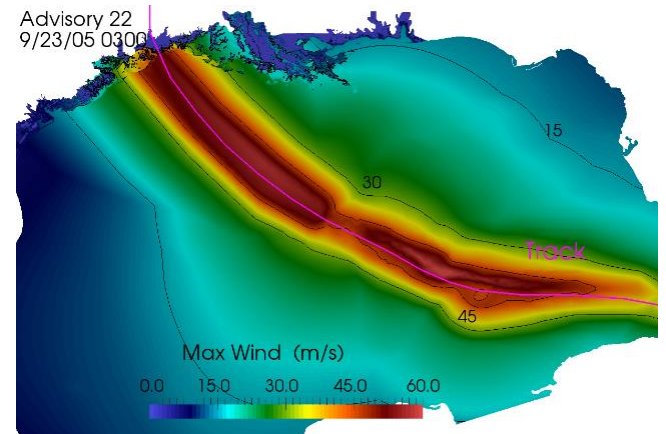

(c)

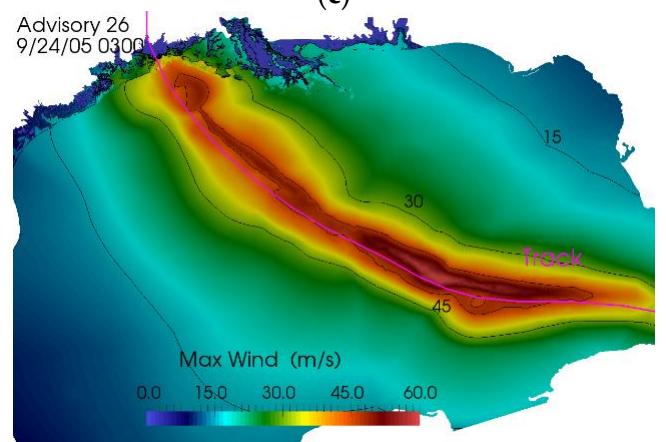

(e)

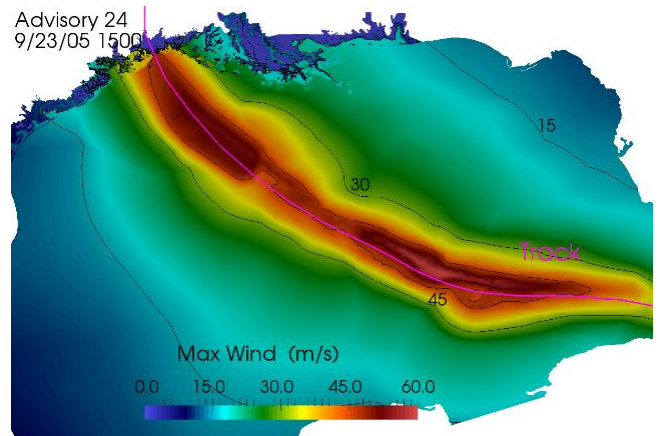

(d)

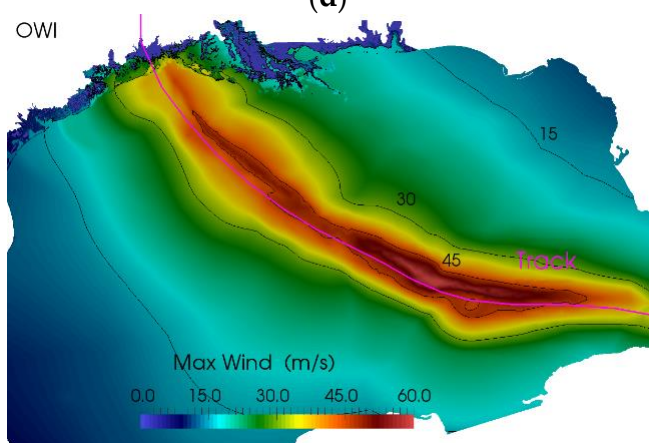

(f)

Figure 9. Rita maximum wind track plots using wind fields from Advisories in GAHM and OWI models. (a) Advisory 18-Adv Run 1, (b) Advisory 20-Adv Run 2, (c) Advisory 22-Adv Run 3, (d) Advisory 24-Adv Run 4, (e) Advisory 26-Adv Run 5, and (f) OWI.

\subsubsection{Comparison of Storm Surges Using Advisories in GAHM and OWI Wind Fields}

Figure 10 shows the maximum water elevation color plots of different storm surge forecasts using advisories in GAHM and the hindcast using OWI wind fields. As anticipated, Adv Run 1 incorrectly shows that the primary location of the storm surge is near Galveston, almost entirely west of the actual track. The rest of the advisory cases show surge locations similar to that of OWI. For all the advisory cases, maximum water elevations are significantly overpredicted in comparison to the OWI. However, the east-west spreads of their water elevation plots are narrower than that of OWI. This finding is not unexpected, given that the advisory wind fields are stronger and narrower. Among all advisory runs, the Adv Run 5 water elevation seems to be the closest to that of OWI. However, most of the wind field of Adv Run 5 is from OWI; the actual contribution of the advisory is only for the last five hours. Figure 11 shows the maximum water velocity color plots of different runs using advisories in GAHM and OWI. The velocity plots show significantly stronger water velocities from advisory wind fields than that of OWI, due to the strong wind field mentioned above.

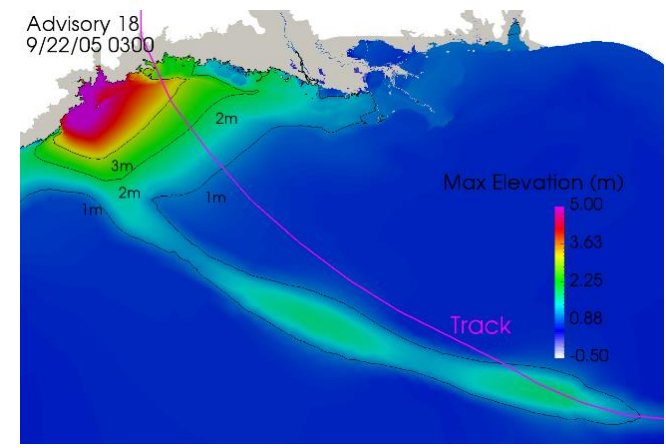

(a)

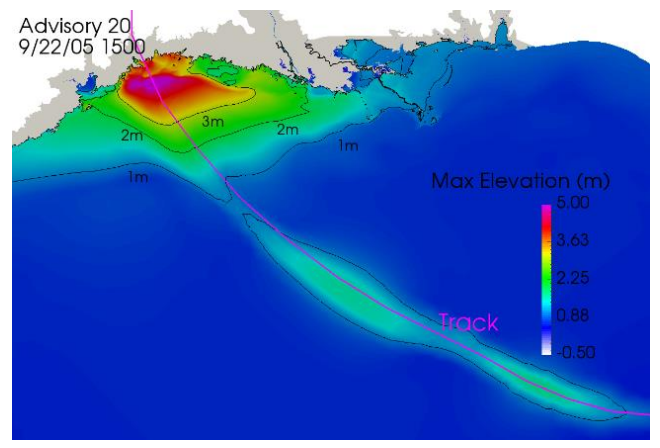

(b)

Figure 10. Cont. 


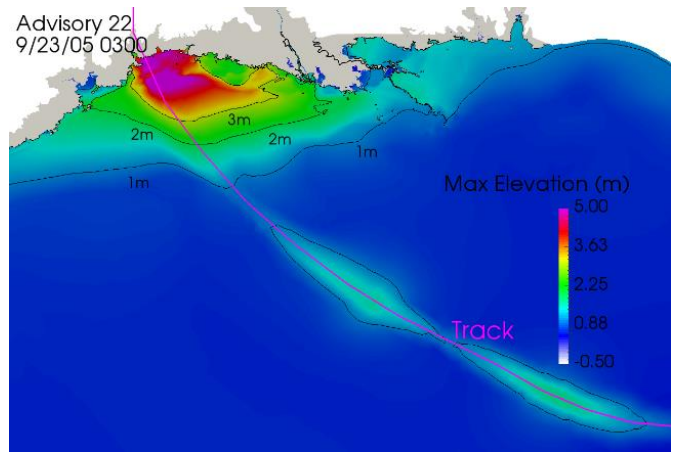

(c)

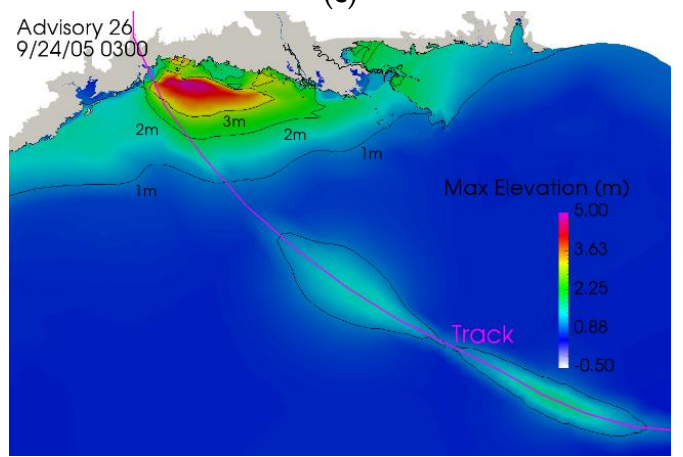

(e)

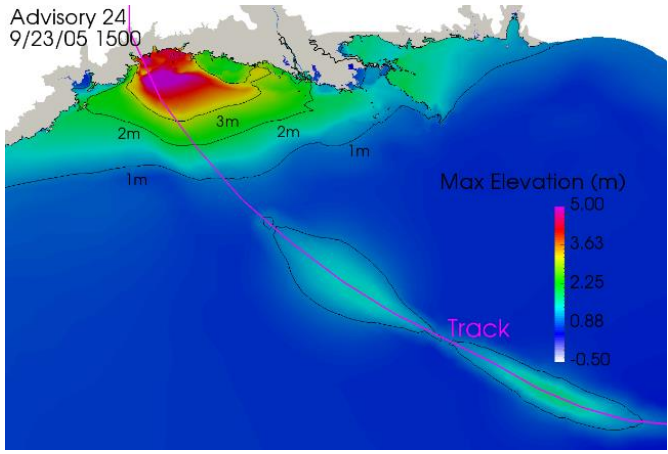

(d)

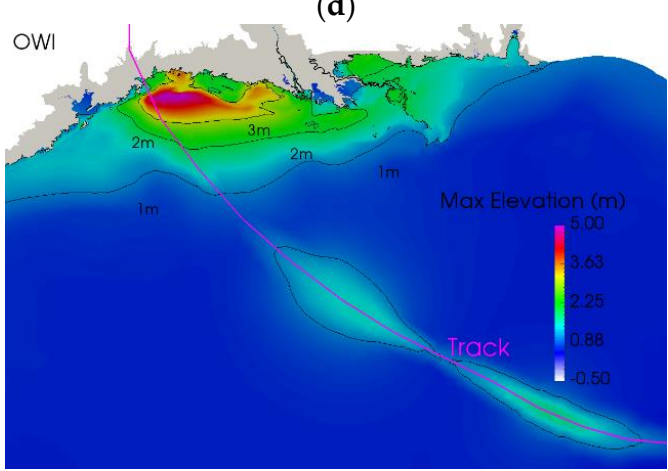

(f)

Figure 10. Rita maximum water elevation from ADCIRC+SWAN simulation results using wind fields from advisories in GAHM and OWI models. (a) Advisory 18-Adv Run 1, (b) Advisory 20-Adv Run 2, (c) Advisory 22-Adv Run 3, (d) Advisory 24-Adv Run 4, (e) Advisory 26-Adv Run 5, and (f) OWI.

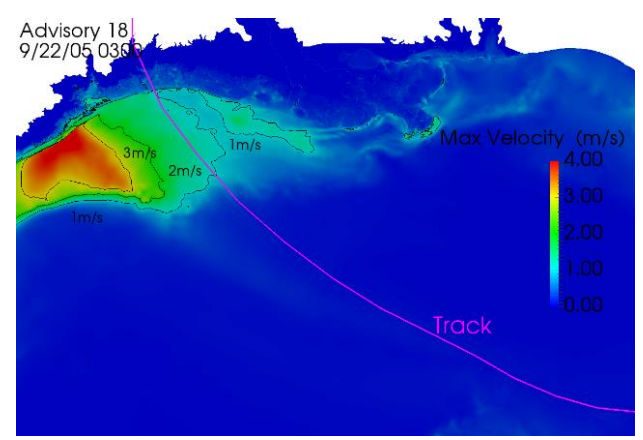

(a)

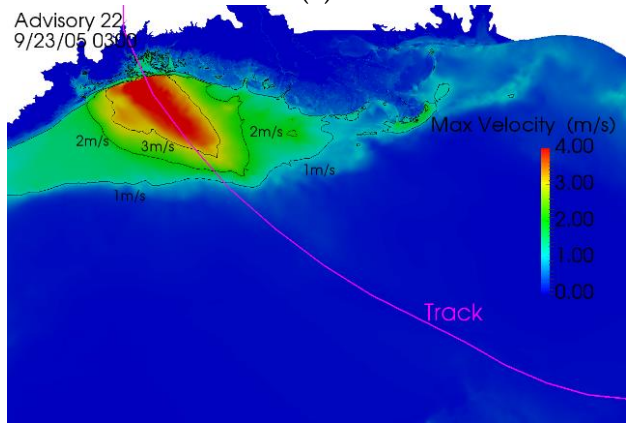

(c)

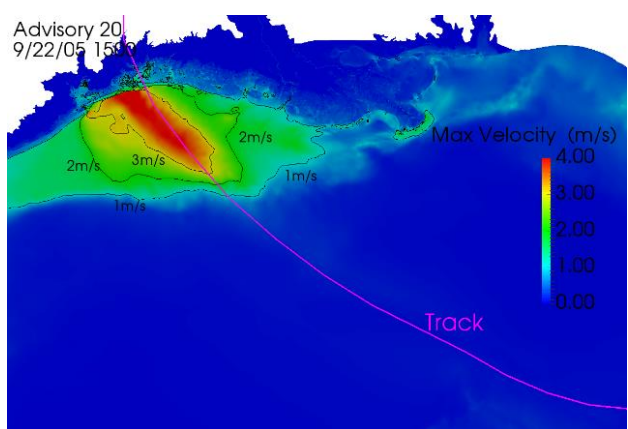

(b)

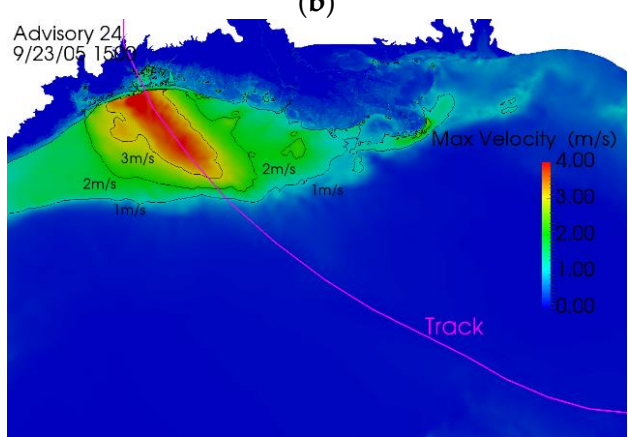

(d)

Figure 11. Cont. 


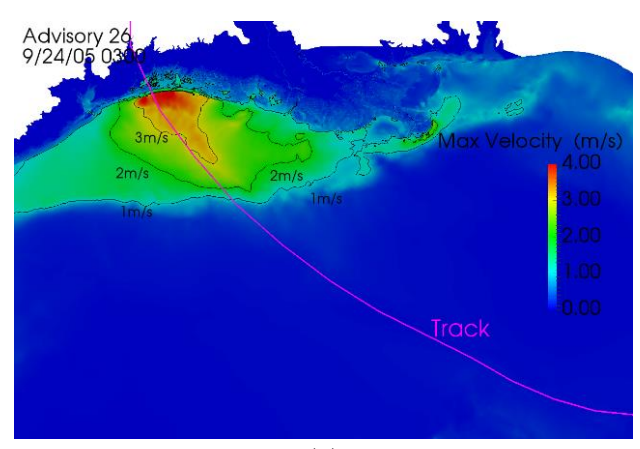

(e)

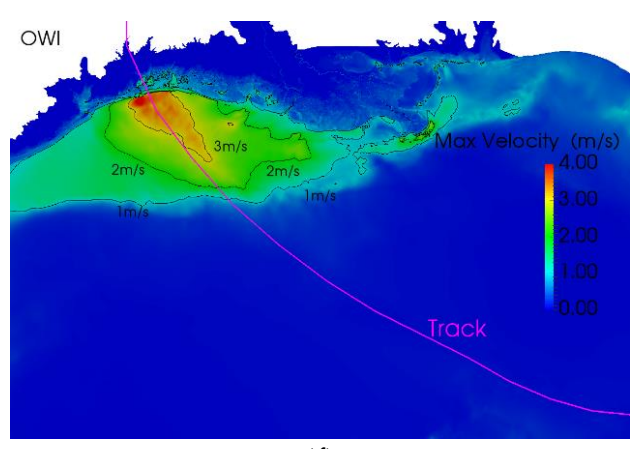

(f)

Figure 11. Rita maximum water velocity from ADCIRC+SWAN simulation results using wind fields from advisories in GAHM and OWI models. (a) Advisory 18-Adv Run 1, (b) Advisory 20-Adv Run 2, (c) Advisory 22-Adv Run 3, (d) Advisory 24-Adv Run 4, (e) Advisory 26-Adv Run 5, and (f) OWI.

\subsubsection{Quantitative Differences between Advisories in GAHM Forecast and OWI Hindcast}

To quantify differences, maximum wind, maximum water elevation and velocity of advisory cases were subtracted from those of the OWI case. For brevity, differences only between OWI and Adv Run 3 results are reported here. Figure 12a shows that the Advisory 22 maximum wind speed near the coastal regions was stronger by about $20 \mathrm{~m} / \mathrm{s}$ than that of OWI. The advisory wind field was consistently higher on both sides of the track than that of OWI. As seen in Figure 12b, the advisory wind vortex was strong and more symmetric than that of OWI. The maximum water elevation generated by Adv Run 3 wind field was higher by $1 \mathrm{~m}$ near the coast. The maximum water velocity generated by the advisory wind field was consistently higher by $1 \mathrm{~m} / \mathrm{s}$ as well. Both findings can be associated with the higher wind speed of Adv Run 3 than that of OWI.

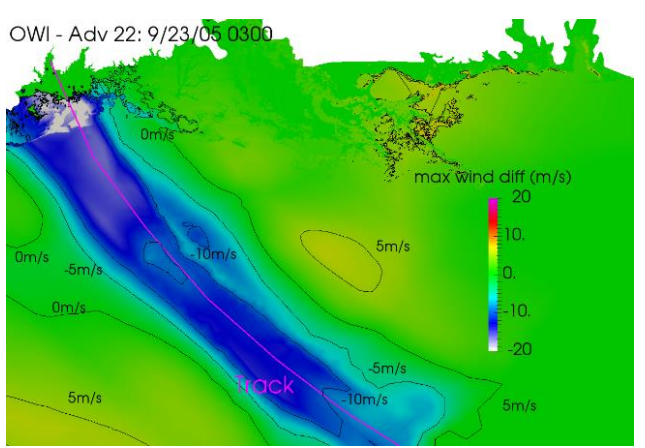

(a)

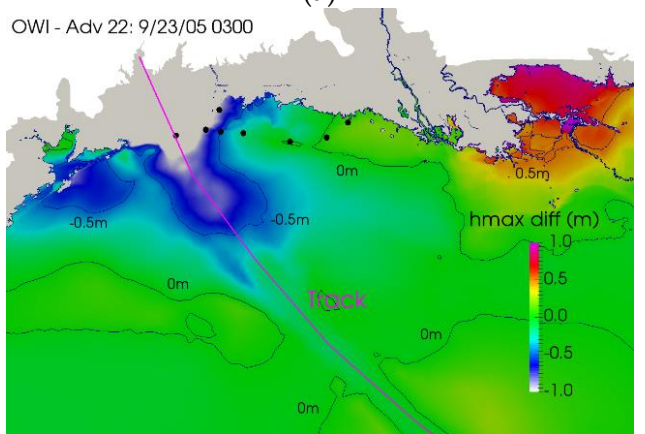

(c)

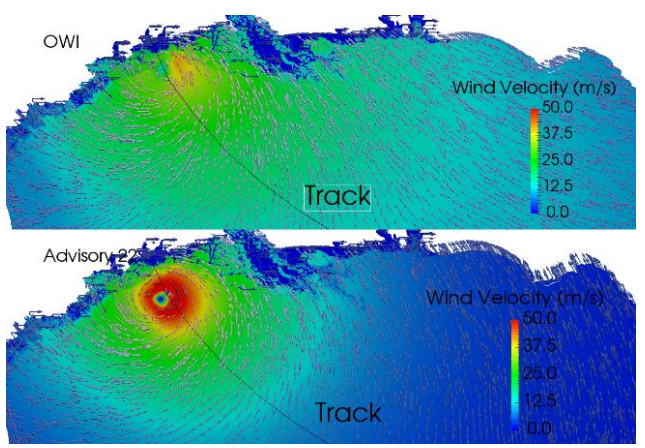

(b)

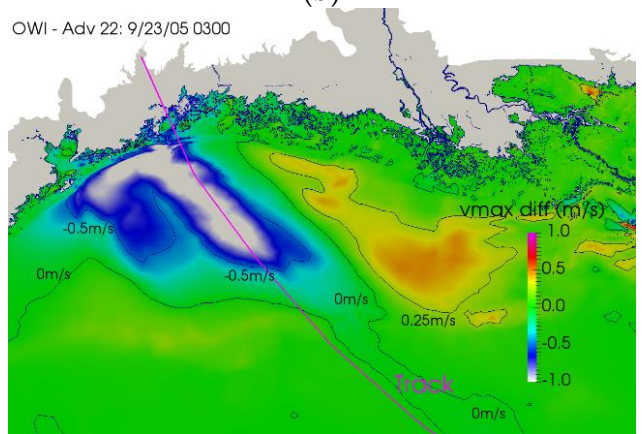

(d)

Figure 12. Differences and contrasts between OWI and Adv Run 3 hindcast results of Hurricane Rita storm surges: (a) difference of maximum wind speed, (b) contrast of wind vectors at landfall, (c) difference of maximum water elevation, and (d) difference of water velocity. The black dots are the locations of eight stations listed in Table 2. 


\subsubsection{Comparison of Surge Time Series Using Advisories and Best Track in GAHM and OWI Winds}

The ADCIRC+SWAN water level time series were compared to observed water levels at stations (displayed on Figure 1b). Away from landfall at station (J), Figure 13a indicates that Adv Run 3-5 predicted the peak well, but with a phase lead. Both Adv Runs 1 and 2 underpredicted the peak. However, Adv Run 1 does not have a phase difference, which could be related to the distance between the station and landfall location wrongfully predicted by this advisory.

In the region of landfall, Figure 13b-e at stations (H, I, D, and F), Adv Run 1 underpredicted the peak as expected due to the inaccurate landfall location. Adv Run 2, in general, predicted the peak well without much phase difference. Adv Runs 3 and 4 overpredicted the peak with some phase delay by about $2 \mathrm{~h}$. A careful inspection of these advisory wind fields revealed that their landfall locations were slightly to the west of the actual/observed landfall. Adv Run 3 had a landfall slightly more west than that of Adv Run 4, and hence it had longer peak delays, up to $2 \mathrm{~h}$, for all stations. Adv Run 5 seemed to have a reasonable peak without much phase difference. However, it contained only $5 \mathrm{~h}$ of advisory wind on top of a wind field mostly produced by OWI forcing.

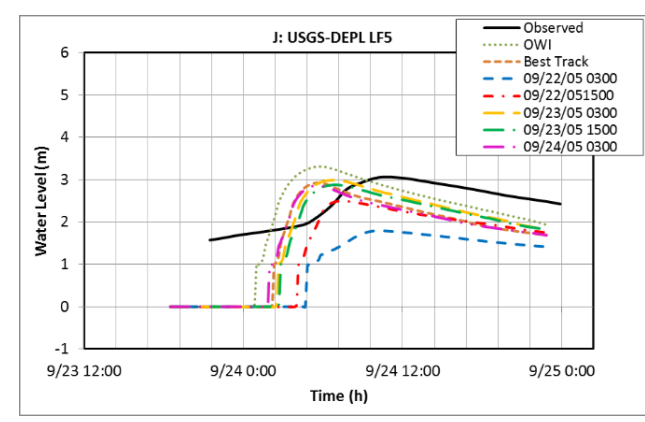

(a)

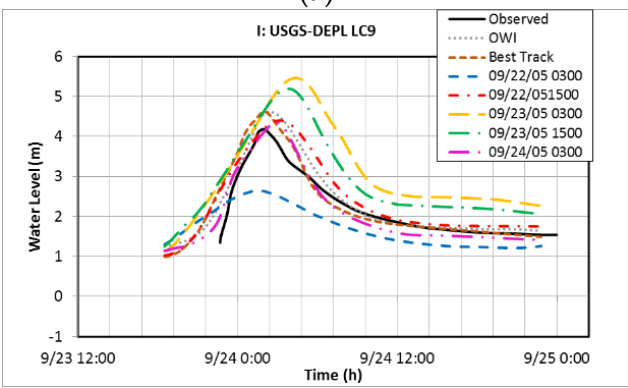

(c)

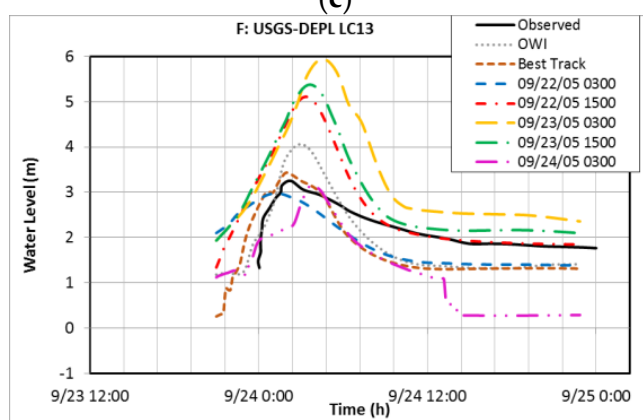

(e)

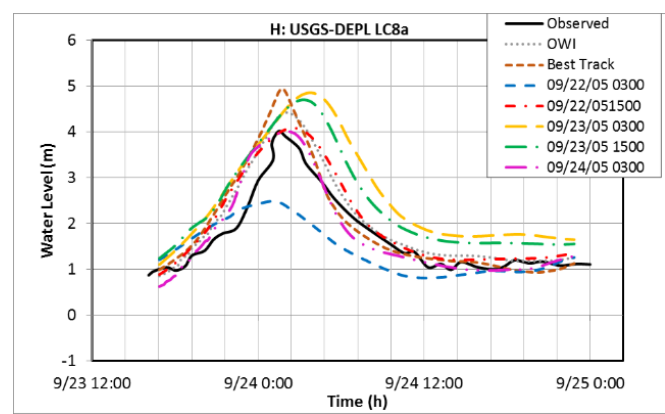

(b)

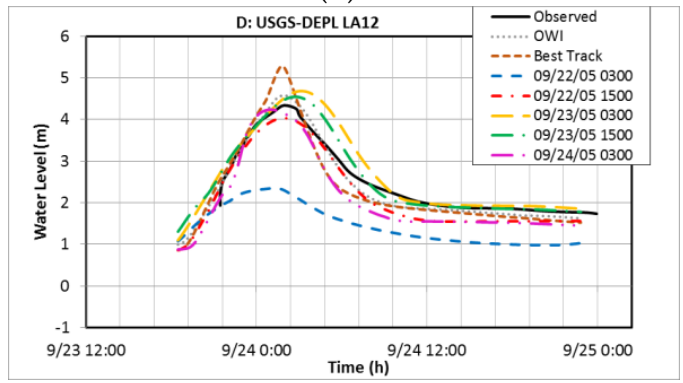

(d)

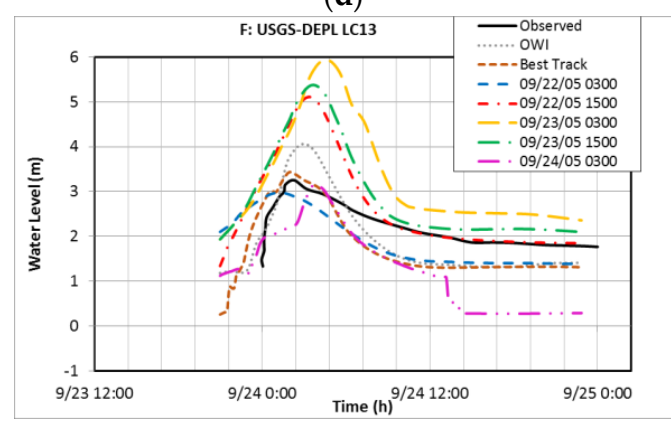

(f)

Figure 13. Cont. 


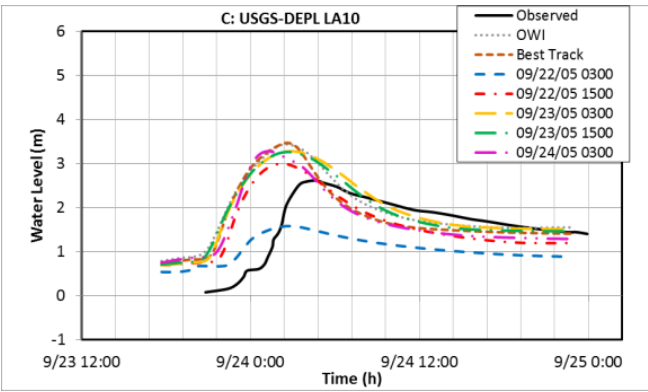

(g)

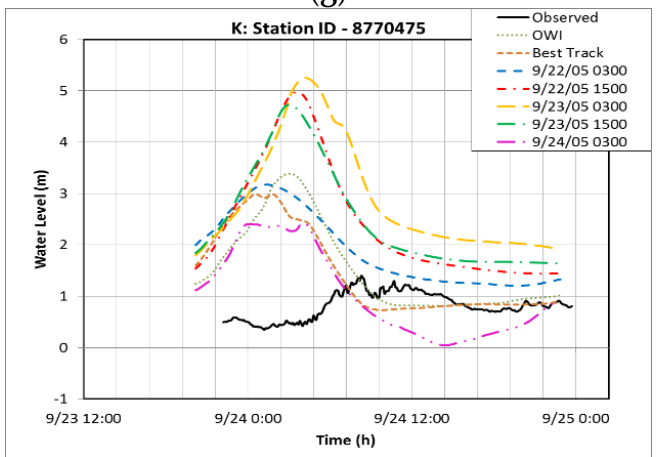

(i)

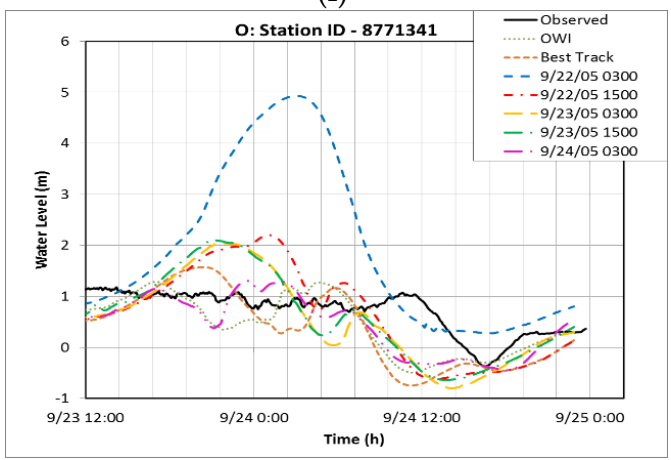

$(\mathbf{k})$

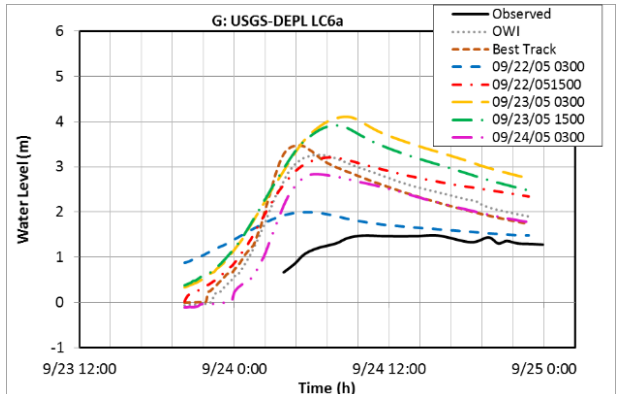

(h)

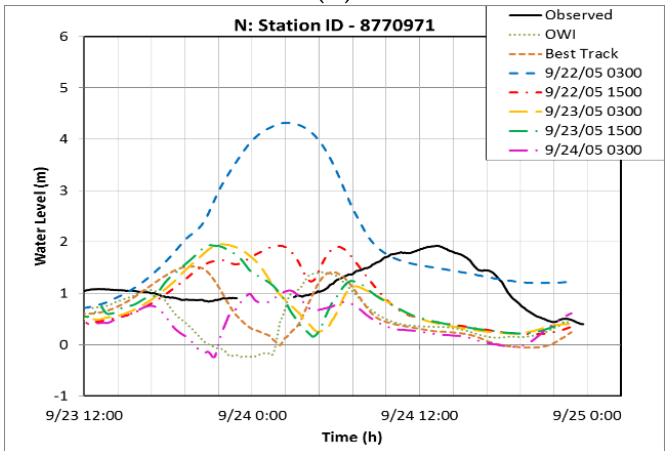

(j)

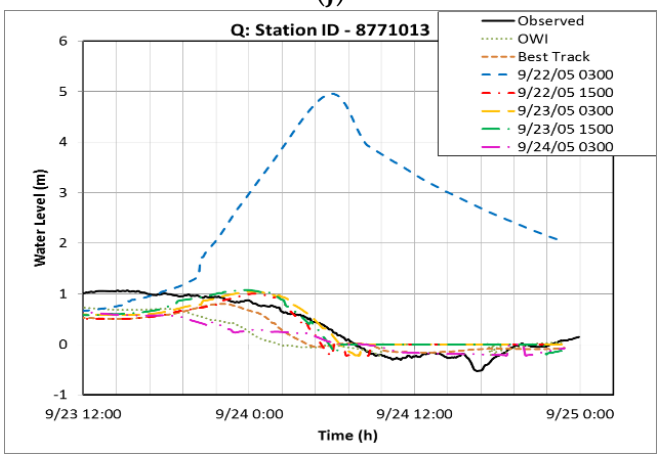

(1)

Figure 13. Effect of wind fields from Advisories in GAHM and OWI models: Observed and ADCIRC+SWAN modeled significant water level time series at different observation stations during the time of Hurricane Rita (9/22-25/05). (a) J-USGS-DEPL LF5; (b) H-USGS-DEPL LC8a; (c) I-USGS-DEPL LC9; (d) D-USGS-DEPL LA12; (e) F-USGS-DEPL LC13; (f) E-USGS-DEPL LA9; (g) C-USGS-DEPL LA10; (h) G-USGS-DEPL LC6a; (i) K-ID 8770570, Sabine Pass North, TX; (j) N-ID 8770971, Rollover Pass, TX; (k) O-ID 8771341, Galveston Bay Entrance, North Jetty, TX; (l) Q-ID 8771013, Eagle Point, Galveston Bay, TX. (Advisory 18-Adv Run 1: 9/22/05 0300; Advisory 20-Adv Run 2: 9/22/05 1500; Advisory 22-Adv Run 3: 9/23/05 0300; Advisory 24—Adv Run 4: 9/23/05 1500; Advisory 26-Adv Run 5: 9/24/05 0300).

At inland stations (E, C, and G) (Figure 13f-h), Adv Run 1 underpredicted the water elevation peak, as expected. For station E, Adv 2-5 performed better than that of OWI. Adv 2-5 runs seemed to predict the water peak similarly to that of OWI for station C. For station G, Adv Runs 2 and 5 performed better than OWI, but Adv Runs 3 and 4 overpredicted the peak with reduced phase differences compared to the observed data. The actual phase difference, either early or delayed arrival, depended on landfall locations, wind field width and strength, locations of the stations and their connectivity with water passages, etc.

As shown in Figure 13i-k, advisories in GAHM winds significantly overpredict surges, although the phase leads are not significantly different than those of OWI surges. As expected, Adv Run 1 is the worst run due to an incorrect landfall location. The double surge peaks are predicted by advisories in 
GAHM at stations N and O, similar to those of OWI. As shown in Figure 131, the Galveston Bay station $\mathrm{Q}$ is away from the direct path of surge propagation and all but Adv Run 1 cases generally predict the peak well with few phase differences.

\subsubsection{Comparison of High Water Mark Using Advisories and Best Track in GAHM and OWI Winds}

The peak water levels were compared for each of the simulations to measured HWMs [64] in Figure 14. The summarized statistics for all HWM analyses using only wet locations are given in Table 6 . Since the advisory wind field bands are narrower, but stronger than that of OWI, high localized surges wetted HWMs within their bounds, while many HWMs locations remained dry. All advisory runs have more, ranging from 9 to 48, dry locations than that of OWI or those of WRF. Most advisory runs, except for Adv Run 3 produced low correlation coefficients since plot data are scattered. A simulation such as Adv Run 3 may produce less accurate inundation extent yet score a high correlation coefficient since dry locations are not plotted and are ignored when computing the statistics. The comparison against the orange parity line shows that some wet HWMs are overpredicted by $1 \mathrm{~m}$ or more by most advisory runs. Considering only the wet nodes, the Adv Run 3 has lower $\mathrm{E}_{\mathrm{RMS}}, \bar{E}, B_{M N}, M A E$, and $E_{N O R M}$ error values than those of OWI. However, the scatter indices ( $\sigma$ and $S I$ ) of Adv Run 3 are larger than those of OWI.

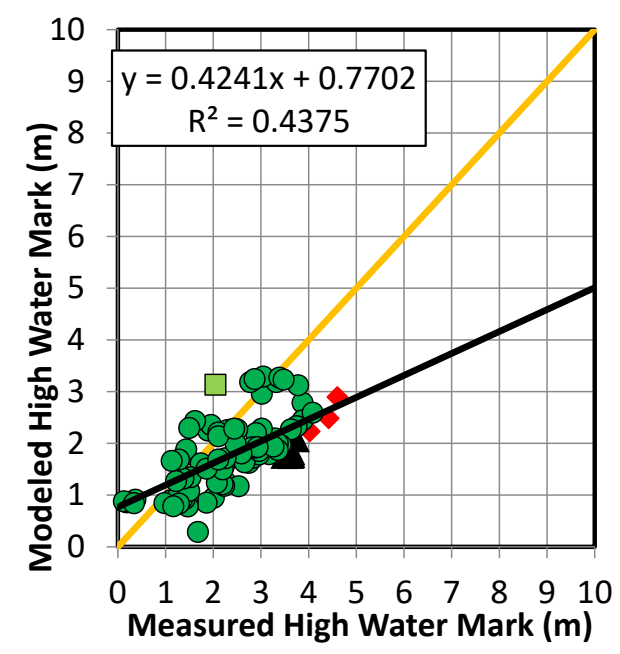

(a)

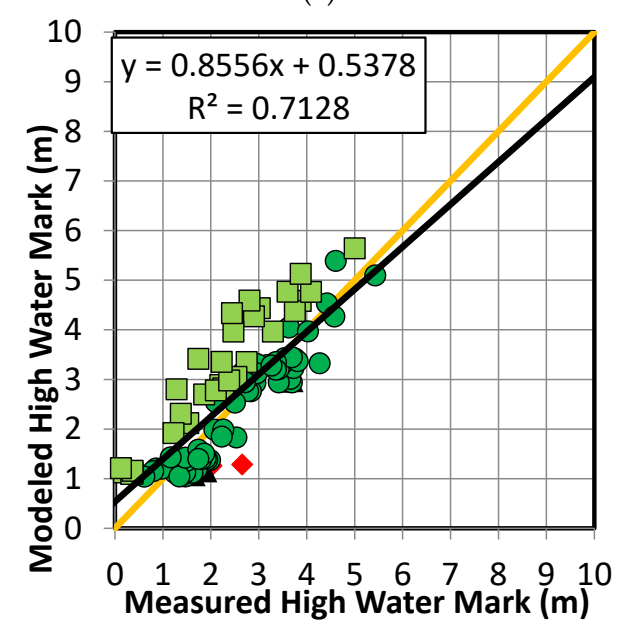

(c)

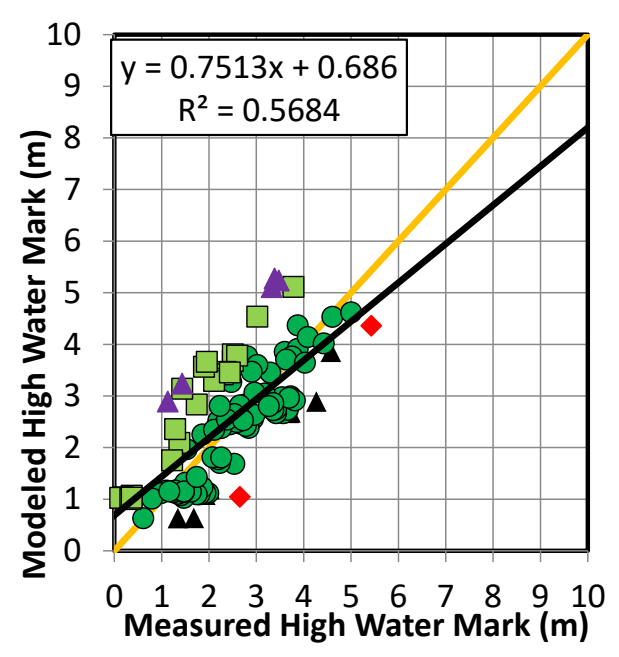

(b)

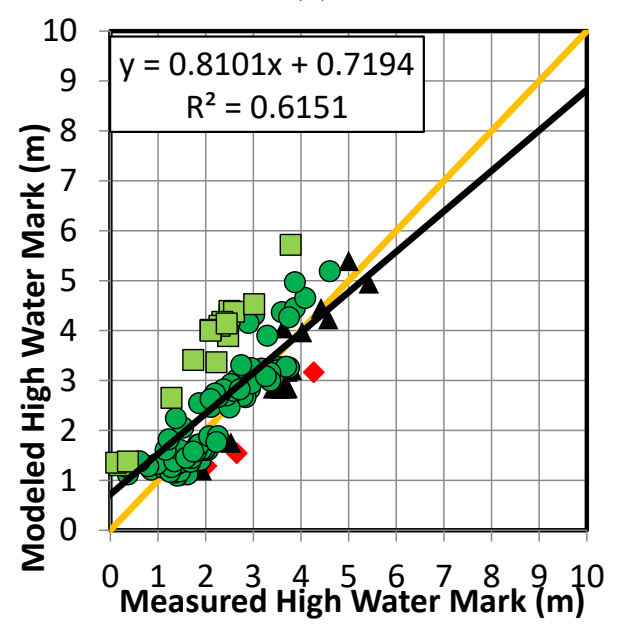

(d)

Figure 14. Cont. 


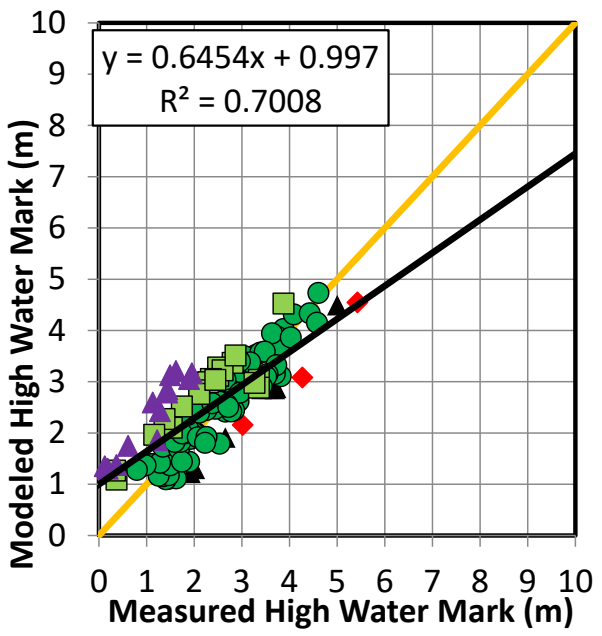

(e)

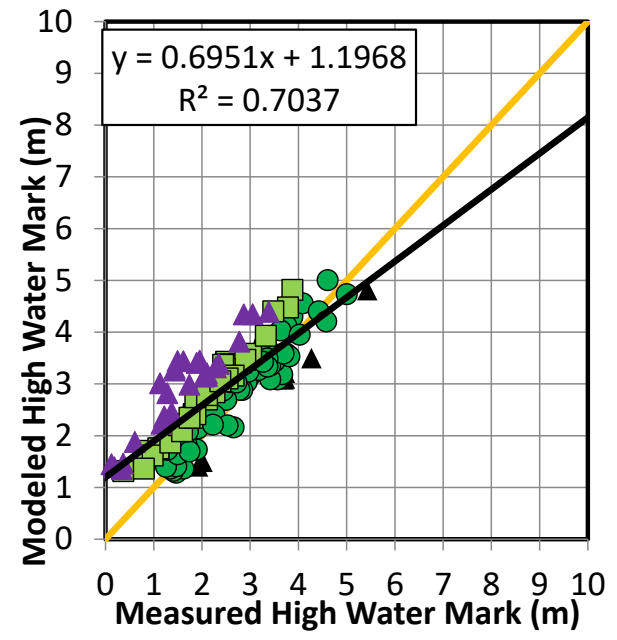

(f)

Figure 14. Scatter plots of Rita HWM's from ADCIRC+SWAN simulations using wind fields from advisories in GAHM and OWI. (a) Advisory 18-Adv Run 1, (b) Advisory 20-Adv Run 2, (c) Advisory 22-Adv Run 3, (d) Advisory 24-Adv Run 4, (e) Advisory 26-Adv Run 5, and (f) OWI. Red diamond and black triangles indicate underprediction by the model; purple triangles and light green squares indicate overprediction. Dark green circles indicate a match within $0.5 \mathrm{~m}$. The black line represents the best fit lines. The orange line represents the parity.

Table 6. HWM error statistics for Rita simulations using forecasted wind fields from archived Advisories.

\begin{tabular}{|c|c|c|c|c|c|c|c|c|c|c|}
\hline Case & $R^{2}$ & $\mathrm{E}_{\mathrm{RMS}}(\mathrm{m})$ & $\bar{E}(\mathrm{~m})$ & $\mathrm{B}_{\mathrm{MN}}(-)$ & $\sigma(\mathrm{m})$ & SI (-) & MAE (m) & $\mathrm{E}_{\text {NORM }}(-)$ & Dry & Wet \\
\hline Advisory 18: Adv Run 1 & 0.438 & 1.050 & -0.611 & -0.253 & 0.827 & 0.529 & 0.850 & 0.151 & 48 & 96 \\
\hline Advisory 20: Adv Run 2 & 0.568 & 0.675 & 0.091 & 0.038 & 0.820 & 0.526 & 0.659 & 0.095 & 23 & 121 \\
\hline Advisory 22: Adv Run 3 & 0.713 & 0.496 & 0.193 & 0.080 & 0.680 & 0.436 & 0.553 & 0.069 & 36 & 108 \\
\hline Advisory 24: Adv Run 4 & 0.615 & 0.663 & 0.266 & 0.110 & 0.773 & 0.496 & 0.620 & 0.094 & 23 & 121 \\
\hline Advisory 26: Adv Run 5 & 0.701 & 0.423 & 0.167 & 0.071 & 0.631 & 0.409 & 0.508 & 0.062 & 9 & 135 \\
\hline OWI (repeated) & 0.704 & 0.598 & 0.480 & 0.203 & 0.609 & 0.394 & 0.616 & 0.088 & 7 & 137 \\
\hline Best Track (repeated) & 0.625 & 0.591 & 0.138 & 0.056 & 0.759 & 0.480 & 0.625 & 0.081 & 23 & 121 \\
\hline
\end{tabular}

\section{Concluding Remarks}

The objective of this study was to learn how forecasted meteorological forcing from different sources influence storm surge generation and propagation during a hurricane. Numerical experiments were performed with different wind fields from OWI and the Best track in GAHM to hindcast Hurricane Rita surges. In addition, WRF and forecast/advisories from the National Hurricane Center in GAHM were used to understand how forecasted wind fields impact storm surge generation and propagation in real time. The OWI wind field was used for the period before the WRF or advisory in GAHM was initialized. These wind fields were used as meteorological forcing in the ADCIRC+SWAN coupled model. The ADCIRC+SWAN setup of Kerr et al. [56] was taken as the benchmark, except that the semi-implicit solver was used in the present study. The OWI model was used as the default wind model, and all results were compared against it and the observed data. Statistical characterizations of different cases were reported, and summarized in Table 7.

Table 7. Summarized HWM error statistics for Rita surge forecast and hindcast using different wind fields.

\begin{tabular}{ccccccccccc}
\hline Case & $\boldsymbol{R}^{2}$ & $\mathbf{E}_{\text {RMS }}(\mathbf{m})$ & $\overline{\mathbf{E}}(\mathbf{m})$ & $\mathbf{B}_{\mathbf{M N}}(-)$ & $\boldsymbol{\sigma}(\mathbf{m})$ & SI (-) & MAE (m) & $\mathbf{E}_{\text {NORM }}(-)$ & Dry & Wet \\
\hline OWI & 0.704 & 0.598 & 0.480 & 0.203 & 0.609 & 0.394 & 0.616 & 0.088 & 7 & 137 \\
Best Track in GAHM & 0.625 & 0.591 & 0.138 & 0.056 & 0.759 & 0.480 & 0.625 & 0.081 & 23 & 121 \\
WRF Run 3 & 0.745 & 0.515 & 0.391 & 0.166 & 0.604 & 0.392 & 0.564 & 0.077 & 9 & 135 \\
Adv Run 3 & 0.713 & 0.496 & 0.193 & 0.080 & 0.680 & 0.436 & 0.553 & 0.069 & 36 & 108 \\
\hline
\end{tabular}


The Best track in GAHM had a stronger and narrower wind field than that of OWI. The station time series from the surge hindcast of Best track behaved similarly to that of OWI. Time series results of these hindcasts compared well with observed data with some overprediction and phase lead. Early peak arrivals are results of quick surge propagations. The HWM correlation coefficient for the Best track in the GAHM model was only 0.625 with 23 dry locations that were excluded, whereas it was 0.704 for OWI with seven excluded dry locations. Considering only the wet stations, the error indices are lower for Best track in GAHM than those of OWI, but their scatter indices are larger (see Table 7). The wet HWMs of the surge hindcast using OWI and Best track in GAHM wind fields compared well with the measured data with some overpredictions.

Weather Research and Forecasting forecast wind fields were weaker, but wider than that OWI. In general, WRF hurricane track was correct, but without the actual curvature of the storm. The forecast initialized at 09/23/2005 0000 UTC had a landfall slightly west of the actual landfall. This in turn, reduced time series surge peak arrival gaps from the observed data. Overall, time series peaks compared well with the observed data with some overprediction and reduced phase difference. The HWM correlation coefficient for the WRF Run 3 case initialized at 09/23/2005 0000 UTC was 0.745 with nine excluded dry locations, which is remarkable as a forecast. Some low surge HWMs were overpredicted and high surge HWMs were underpredicted by all WRF cases. Both error and scatter indices are lower for the WRF Run 3 case than those of OWI (see Table 7).

The advisories in the GAHM model produced stronger, but narrower wind fields. The earliest advisory used in the present study was Advisory 18-Adv Run 1, issued at 09/22/2005 0300 UTC. This advisory produced incorrect location of the landfall, and all results were off, indicating the fact that early advisories should be used with caution. Otherwise, rest of the advisories produced reasonable tracks, except for stronger and narrower wind fields than that of OWI. Such wind fields overpredicted surge forecasts with phase leads, as the time series analyses reflect the fact. The HWM correlation coefficient for Advisory 22-Adv Run 3, issued at 09/23/2005 0300 UTC was 0.713 with 36 excluded dry locations. The HWMs surge levels in wet locations matched well with measured data, although there are some overpredictions by $1 \mathrm{~m}$ or more. The error indices are lower for $\mathrm{Adv}$ Run 3 in GAHM than those of OWI, but their scatter indices are larger (see Table 7). Although they are all widely used due to the simplicity of the GAHM parametric wind model, the advisory or Best track in GAHM does not perform as well as OWI and/or WRF forecast in storm surge generation and propagation for Hurricane Rita. Recall that Best track in GAHM uses limited Best track wind data to recreate a wind field using GAHM model. The OWI uses observational data to form a wind field after the hurricane passes. On the other hand, WRF is a full physics model that forecasts a wind field. A more comprehensive generalization cannot be made without investigating more hurricanes using a similar technique used in the present study, which authors are planning to do next. Since OWI and the Best track in GAHM are not available for a forecast period, perhaps using both WRF and advisories in GAHM to forecast a comprehensive picture of the storm surge in real time during an impending hurricane will be useful.

Author Contributions: A.M. performed all runs, post processed results, and initial analysis. M.K.A. designed the study, ran some cases, and analyzed results. J.G.F. helped with the ADCIRC + SWAN issues and wind model setups, did critical reviews, and S.K.H. secured student's funding.

Funding: This research received no external funding.

Acknowledgments: Authors are grateful to the University of North Carolina's Renaissance Computing Institute for the access to their high-performance computing platform.

Conflicts of Interest: The authors declare sole responsibility of the research results. 


\section{References}

1. Forbes, C.; Rhome, J. An automated operational storm surge prediction system for the national hurricane center. In Estuarine and Coastal Modeling (2011); American Society of Civil Engineers: Reston, VA, USA, 2013; pp. 213-229.

2. Zhang, K.; Li, Y.; Liu, H.; Rhome, J.; Forbes, C. Transition of the coastal and estuarine storm tide model to an operational storm surge forecast model: A case study of the Florida coast. Weather Forecast. 2013, 28, 1019-1037. [CrossRef]

3. Irish, J.L.; Song, Y.K.; Chang, K.A. Probabilistic hurricane surge forecasting using parameterized surge response functions. Geophys. Res. Lett. 2011, 38. [CrossRef]

4. Kennedy, A.B.; Westerink, J.J.; Smith, J.M.; Hope, M.E.; Hartman, M.; Taflanidis, A.A.; Tanaka, S.; Westerink, H.; Cheung, K.F.; Smith, T.; et al. Tropical cyclone inundation potential on the Hawaiian Islands of Oahu and Kauai. Ocean Model. 2012, 52, 54-68. [CrossRef]

5. Simm, J.D.; Guise, A.; Robbins, D.; Engle, J. US North Atlantic coast comprehensive study: Resilient adaptation to increasing risk. In Proceedings of the ICE Coastal Management 2015, Amsterdam, The Netherlands, 7-9 September 2015.

6. Taflanidis, A.A.; Kennedy, A.B.; Westerink, J.J.; Smith, J.; Cheung, K.F.; Hope, M.; Tanaka, S. Rapid assessment of wave and surge risk during landfalling hurricanes: Probabilistic approach. J. Waterw. Port Coast. Ocean Eng. 2012, 139, 171-182. [CrossRef]

7. Taflanidis, A.A.; Jia, G.; Kennedy, A.B.; Smith, J.M. Implementation/optimization of moving least squares response surfaces for approximation of hurricane/storm surge and wave responses. Nat. Hazards 2013, 66, 955-983. [CrossRef]

8. Ramos Valle, A.N.; Curchitser, E.N.; Bruyere, C.L.; Fossell, K.R. Simulating Storm Surge Impacts with a Coupled Atmosphere-Inundation Model with Varying Meteorological Forcing. J. Mar. Sci. Eng. 2018, 6, 35. [CrossRef]

9. Dresback, K.M.; Fleming, J.G.; Blanton, B.O.; Kaiser, C.; Gourley, J.J.; Tromble, E.M.; Luettich, R.A., Jr.; Kolar, R.L.; Hong, Y.; Van Cooten, S.; et al. Skill assessment of a real-time forecast system utilizing a coupled hydrologic and coastal hydrodynamic model during Hurricane Irene (2011). Cont. Shelf Res. 2013, 71, 78-94. [CrossRef]

10. Forbes, C.; Rhome, J.; Mattocks, C.; Taylor, A. Predicting the storm surge threat of Hurricane Sandy with the National Weather Service SLOSH model. J. Mar. Sci. Eng. 2014, 2, 437-476. [CrossRef]

11. Suh, S.W.; Lee, H.Y.; Kim, H.J.; Fleming, J.G. An efficient early warning system for typhoon storm surge based on time-varying advisories by coupled ADCIRC and SWAN. Ocean Dyn. 2015, 65, 617-646. [CrossRef]

12. Dietrich, J.C.; Muhammad, A.; Curcic, M.; Fathi, A.; Dawson, C.N.; Chen, S.S.; Luettich, R.A., Jr. Sensitivity of storm surge predictions to atmospheric forcing during hurricane ISAAC. J. Waterw. Port Coast. Ocean Eng. 2017, 144, 04017035. [CrossRef]

13. Ding, Y.; Ding, T.; Jia, Y.; Altinakar, M. Developing a Tropical Cyclone Parametric Wind Model with Landfall Effect for Real-Time Prediction of Wind and Storm Surge. In Proceedings of the 2013 IAHR Congress, Tsinghua University Press, Beijing, China, 8-13 September 2013.

14. Forbes, C.; Luettich, R.A., Jr.; Mattocks, C.A.; Westerink, J.J. A retrospective evaluation of the storm surge produced by Hurricane Gustav (2008): Forecast and hindcast results. Weather Forecast. 2010, 25, 1577-1602. [CrossRef]

15. Yoon, J.J.; Shim, J.S. Development of a near real-time forecasting system for storm surge and coastal inundation. J. Coast. Res. 2016, 75, 1427-1431. [CrossRef]

16. Grell, G.; Dudhia, J.; Stauffer, D. A Description of the Fifth-Generation Penn State/NCAR Mesoscale Model (MM5); NCAR Techical Note NCAR/TN-398 + STR; National Center for Atmospheric Research: Boulder, CO, USA, $1994 ; 117 p$.

17. Kurihara, Y.; Tuleya, R.E.; Bender, M.A. The GFDL hurricane prediction system and its performance in the 1995 hurricane season. Mon. Weather Rev. 1998, 126, 1306-1322. [CrossRef]

18. Corbosiero, K.L.; Wang, W.; Chen, Y.; Dudhia, J.; Davis, C. Advanced research WRF high frequency model simulations of the inner core structure of Hurricanes Katrina and Rita (2005). In Proceedings of the 8th WRF User's Workshop, National Center for Atmospheric Research, Boulder, CO, USA, June 2007; pp. 11-15. 
19. Holland, G.J. An analytic model of the wind and pressure profiles in hurricanes. Mon. Weather Rev. 1980, 108, 1212-1218. [CrossRef]

20. Chow, S.H. A Study of the Wind Field in the Planetary Boundary Layer of a Moving Tropical Cyclone. Master's Thesis, School of Engineering and Science, New York University, New York, NY, USA, 1970.

21. Cardone, V.J.; Young, J.D.; Pierson, W.J.; Moore, R.K.; Greenwood, J.A.; Greenwood, C.; Fung, A.K.; Salfi, R.; Chan, H.L.; Afarani, M.; et al. The Measurement of the Winds near the Ocean Surface with a Radiometer-Scatterometer on Skylab; E76-10187 (Contract NAS9-13642), Available as NASA CR-147487; CUNY Inst. Marine \& Atmospheric Sci. and Univ. Kansas Space Technol. Center: USA, 1976.

22. Thompson, E.F.; Cardone, V.J. Practical modeling of hurricane surface wind fields. J. Waterw. Port Coast. Ocean Eng. 1996, 122, 195-205. [CrossRef]

23. Vickery, P.J.; Skerlj, P.F.; Steckley, A.C.; Twisdale, L.A. Hurricane wind field model for use in hurricane simulations. J. Struct. Eng. 2000, 126, 1203-1221. [CrossRef]

24. Cox, A.T.; Greenwood, J.A.; Cardone, V.J.; Swail, V.R. An interactive objective kinematic analysis system. In Proceedings of the Fourth International Workshop on Wave Hindcasting and Forecasting, Banff, Alberta, 16-20 October 1995; pp. 109-118.

25. Cardone, V.J.; Cox, A.T. Tropical cyclone wind field forcing for surge models: Critical issues and sensitivities. Nat. Hazards 2009, 51, 29-47. [CrossRef]

26. Powell, M.D.; Houston, S.H.; Amat, L.R.; Morisseau-Leroy, N. The HRD real-time hurricane wind analysis system. J. Wind Eng. Ind. Aerodyn. 1998, 77, 53-64. [CrossRef]

27. Lionello, P.; Malguzzi, P.; Buzzi, A. Coupling between the atmospheric circulation and the ocean wave field: An idealized case. J. Phys. Oceanogr. 1998, 28, 161-177. [CrossRef]

28. Chen, S.S.; Zhao, W.; Donelan, M.A.; Price, J.F.; Walsh, E.J. The CBLAST-Hurricane program and the next-generation fully coupled atmosphere-wave-ocean models for hurricane research and prediction. Bull. Am. Meteorol. Soc. 2007, 88, 311-317. [CrossRef]

29. Chen, S.S.; Zhao, W.; Donelan, M.A.; Tolman, H.L. Directional wind-wave coupling in fully coupled atmosphere-wave-ocean models: Results from CBLAST-Hurricane. J. Atmos. Sci. 2013, 70, 3198-3215. [CrossRef]

30. Curcic, M.; Chen, S.S.; Özgökmen, T.M. Hurricane-induced ocean waves and stokes drift and their impacts on surface transport and dispersion in the Gulf of Mexico. Geophys. Res. Lett. 2016, 43, 2773-2781. [CrossRef]

31. Aijaz, S.; Ghantous, M.; Babanin, A.V.; Ginis, I.; Thomas, B.; Wake, G. Nonbreaking wave-induced mixing in upper ocean during tropical cyclones using coupled hurricane-ocean-wave modeling. J. Geophys. Res. Oceans 2017, 122, 3939-3963. [CrossRef]

32. Chen, S.S.; Curcic, M. Ocean surface waves in Hurricane Ike (2008) and Superstorm Sandy (2012): Coupled model predictions and observations. Ocean Model. 2016, 103, 161-176. [CrossRef]

33. Ebersole, B.A.; Westerink, J.J.; Resio, D.T.; Dean, R.G. Performance Evaluation of the New Orleans and Southeast Louisiana Hurricane Protection System, Vol. IV-The Storm; Final Report of the Interagency Performance Evaluation Task Force; US Army Corps of Engineers: Washington, DC, USA, 2007.

34. Hope, M.E.; Westerink, J.J.; Kennedy, A.B.; Kerr, P.C.; Dietrich, J.C.; Dawson, C.; Bender, C.J.; Smith, J.M.; Jensen, R.E.; Zijlema, M.; et al. Hindcast and validation of Hurricane Ike (2008) waves, forerunner, and storm surge. J. Geophys. Res. Oceans 2013, 118, 4424-4460. [CrossRef]

35. Dietrich, J.C.; Zijlema, M.; Westerink, J.J.; Holthuijsen, L.H.; Dawson, C.; Luettich, R.A., Jr.; Jensen, R.E.; Smith, J.M.; Stelling, G.S.; Stone, G.W. Modeling hurricane waves and storm surge using integrally-coupled, scalable computations. Coast. Eng. 2011, 58, 45-65. [CrossRef]

36. Bilskie, M.V.; Hagen, S.C.; Medeiros, S.C.; Cox, A.T.; Salisbury, M.; Coggin, D. Data and numerical analysis of astronomic tides, wind-waves, and hurricane storm surge along the northern Gulf of Mexico. J. Geophys. Res. Oceans 2016, 121, 3625-3658. [CrossRef]

37. Cyriac, R.; Dietrich, J.C.; Fleming, J.G.; Blanton, B.O.; Kaiser, C.; Dawson, C.N.; Luettich, R.A. Variability in Coastal Flooding predictions due to forecast errors during Hurricane Arthur. Coast. Eng. 2018, 137, 59-78. [CrossRef]

38. Lin, N.; Smith, J.A.; Villarini, G.; Marchok, T.P.; Baeck, M.L. Modeling extreme rainfall, winds, and surge from Hurricane Isabel (2003). Weather Forecast. 2010, 25, 1342-1361. [CrossRef] 
39. Knutson, T.R.; Tuleya, R.E. Impact of $\mathrm{CO}_{2}$-induced warming on simulated hurricane intensity and precipitation: Sensitivity to the choice of climate model and convective parameterization. J. Clim. 2004, 17, 3477-3495. [CrossRef]

40. Trenberth, K. Uncertainty in hurricanes and global warming. Science 2005, 308, 1753-1754. [CrossRef]

41. Webster, P.J.; Holland, G.J.; Curry, J.A.; Chang, H.R. Changes in tropical cyclone number, duration, and intensity in a warming environment. Science 2005, 309, 1844-1846. [CrossRef]

42. Haagenson, P.L.; Dudhia, J.; Grell, G.A.; Stauffer, D.R. The Penn State/NCAR Mesoscale Model (MM5) Source Code Documentation; NCAR Tech. Note TN-392+ STR.; NCAR: Boulder, CO, USA, 1994.

43. Knutson, T.R.; Tuleya, R.E. Increased hurricane intensities with $\mathrm{CO}_{2}$-induced warming as simulated using the GFDL hurricane prediction system. Clim. Dyn. 1999, 15, 503-519. [CrossRef]

44. Powers, G.; Huang, X.Y.; Klemp, B.; Shamarock, C.; Dudhia, J.; Gill, O.; Duda, G.; Barker, D.; Wang, W. A Description of the Advanced Research WRF version 3; Technical Report, NCAR Technical Note NCAR/ TN-475+STR; NCAR: Boulder, CO, USA, 2008.

45. Shapiro, L.J. The asymmetric boundary layer flow under a translating hurricane. J. Atmos. Sci. 1983, 40, 1984-1998. [CrossRef]

46. Fleming, J.G.; Fulcher, C.W.; Luettich, R.A.; Estrade, B.D.; Allen, G.D.; Winer, H.S. A real time storm surge forecasting system using ADCIRC. In Estuarine and Coastal Modeling 2007; American Society of Civil Engineers: Reston, VA, USA, 2008; pp. 893-912.

47. Mattocks, C.; Forbes, C.; Ran, L. Design and Implementation of a Real-Time Storm Surge and Flood Forecasting Capability for the State of North Carolina; UNC-CEP Technical Report; University of North Carolina: Chapel Hill, NC, USA, 2006; Volume 30.

48. Mattocks, C.; Forbes, C. A real-time, event-triggered storm surge forecasting system for the state of North Carolina. Ocean Model. 2008, 25, 95-119. [CrossRef]

49. Gao, J.; Luettich, R.; Fleming, J. Development and initial evaluation of a generalized asymmetric tropical cyclone vortex model in ADCIRC. In Proceedings of the 17th ADCIRC Users Group Meeting, Vicksburg, MS, USA, April 2013.

50. Luettich, R.A.; Westerink, J.J.; Scheffner, N.W. ADCIRC: An Advanced Three-Dimensional Circulation Model for Shelves, Coasts and Estuaries; Report 1: Theory and Methodology of ADCIRC-2DDI and ADCIRC-3DL, Technical Report DRP-92-6; Department of the Army, USACE: Washington, DC, USA, 1991.

51. Westerink, J.J.; Luettich, R.A.; Blain, C.A.; Scheffner, N.W. An Advanced Three-Dimensional Circulation Model for Shelves, Coasts and Estuaries; Report 2: Users' Manual for ADCIRC-2DDI; Department of the Army, USACE: Washington, DC, USA, 1992.

52. Kolar, R.L.; Gray, W.G.; Westerink, J.J.; Luettich, R.A. Shallow Water Modeling in Spherical Coordinates: Equation Formulation, Numerical Implementation and Application. J. Hydraul. Res. 1994, 32, 3-24. [CrossRef]

53. Blain, C.A.; Rogers, W.E. Coastal Tide Prediction Using the ADCIRC-2DDI Hydro-Dynamic Finite Element Model: Model Validation and Sensitivity Analyses in the Southern North Sea/English Channel; Technical Report-NRL/FR/7322-98-9682; Office of Naval Research: Arlington, VA, USA, 1998.

54. SWAN_Scientific and Technical Documentation Version 40.91AB. 2013. Delft University of Technology, Environmental Fluid Mechanics Section, 15 July 2017. Available online: http:/ /www.swan.tudelft.nl (accessed on 19 March 2019).

55. Knabb, R.D.; Brown, D.P.; Rhome, J.R. Tropical Cyclone Report, Hurricane Rita, 18-26 September 2005; National Hurricane Center: Miami, FL, USA, 2006; 33p.

56. Kerr, P.C.; Donahue, A.S.; Westerink, J.J.; Luettich, R.A.; Zheng, L.Y.; Weisberg, R.H.; Huang, Y.; Wang, H.V.; Teng, Y.; Forrest, D.R.; et al. U.S. IOOS coastal and ocean modeling testbed: Inter-model evaluation of tides, waves, and hurricane surge in the Gulf of Mexico. J. Geophys. Res. Oceans 2013, 118, 5129-5172. [CrossRef]

57. ATCF System. 2010. Automated Tropical Cyclone Forecasting System-Naval Research Laboratory. 20 July 2017. Available online: https:/ / www.nrlmry.navy.mil/atcf_web/docs/database/new/abrdeck.html (accessed on 19 March 2019).

58. Michalakes, J.; Dudhia, J.; Gill, D.; Klemp, J.; Skamarock, W. Design of a Next Generation Regional Weather Research and Forecast Model; Towards Teracomputing; World Scientific: River Edge, NJ, USA, 1998; pp. 117-124. 
59. Reif, M. Inner-Core Vacillation Cycles of Hurricane Katrina in a Non-Hydrostatic Model. Master's Thesis, Geo- and Atmospheric Sciences, University of Innsbruck, Innsbruck, Austria, 2012.

60. Curcic, M. Explicit Air-Sea Momentum Exchange in Coupled Atmosphere-Wave-Ocean Modeling of Tropical Cyclones. Ph.D. Dissertation, University of Miami, Coral Gables, FL, USA, 2015.

61. Powell, M.D. New findings on hurricane intensity, wind field extent, and surface drag coefficient behavior. In Proceedings of the 10th International Workshop on Wave Hindcasting and Forecasting and Coastal Hazard Symposium, Oahu, HI, USA, 11-16 November 2007.

62. Mukai, A.Y.; Westerink, J.J.; Luettich, R.A., Jr.; Mark, D. Eastcoast 2001, a Tidal Constituent Database for Western North Atlantic, Gulf of Mexico, and Caribbean Sea; No. ERDC/CHL-TR-02-24; Engineer Research and Development Center Vicksburg MS Coastal and Hydraulics Laboratory: Vicksburg, MS, USA, 2002.

63. Lyard, F.; Lefevre, F.; Letellier, T.; Francis, O. Modelling the global ocean tides: Modern insights from FES2004. Ocean Dyn. 2006, 56, 394-415. [CrossRef]

64. USGS Flood Information. USGS Flood Event Viewer: Providing Hurricane and Flood Response Data. 20 July 2017. Available online: https:/ / water.usgs.gov / floods / FEV/ (accessed on 19 March 2019).

65. Akbar, M.K.; Kanjanda, S.; Musinguzi, A. Effect of Bottom Friction, Wind Drag Coefficient, and Meteorological Forcing in Hindcast of Hurricane Rita Storm Surge Using SWAN+ ADCIRC Model. J. Mar. Sci. Eng. 2017, 5, 38. [CrossRef]

(C) 2019 by the authors. Licensee MDPI, Basel, Switzerland. This article is an open access article distributed under the terms and conditions of the Creative Commons Attribution (CC BY) license (http://creativecommons.org/licenses/by/4.0/). 